\title{
Operational climate monitoring from space: the EUMETSAT Satellite Application Facility on Climate Monitoring (CM-SAF)
}

\author{
J. Schulz ${ }^{1}$, P. Albert ${ }^{1}$, H.-D. Behr ${ }^{1}$, D. Caprion ${ }^{2}$, H. Deneke ${ }^{3}$, S. Dewitte ${ }^{2}$, B. Dürr ${ }^{4}$, P. Fuchs ${ }^{1}$, A. Gratzki ${ }^{1}$, \\ P. Hechler ${ }^{1}$, R. Hollmann ${ }^{1}$, S. Johnston ${ }^{5}$, K.-G. Karlsson ${ }^{5}$, T. Manninen ${ }^{6}$, R. Müller ${ }^{1}$, M. Reuter ${ }^{1}$, A. Riihelä ${ }^{6}$, \\ R. Roebeling ${ }^{3}$, N. Selbach ${ }^{1}$, A. Tetzlaff ${ }^{5}$, W. Thomas ${ }^{1}$, M. Werscheck ${ }^{1}$, E. Wolters ${ }^{3}$, and A. Zelenka ${ }^{4}$ \\ ${ }^{1}$ Deutscher Wetterdienst (DWD), Frankfurter Straße 135, 63004 Offenbach, Germany \\ ${ }^{2}$ Royal Meteorological Institute of Belgium (RMI), Ringlaan 3 Avenue Circulaire, 1180 Brussels, Belgium \\ ${ }^{3}$ Koninklijk Nederlands Meteorologisch Instituut (KNMI), Wilhelminalaan 103732 GK De Bilt, The Netherlands \\ ${ }^{4}$ MeteoSchweiz, P.O. Box 514, 8044 Zürich, Switzerland \\ ${ }^{5}$ Swedish Meteorological and Hydrological Institute (SMHI), Folkborgsvägen 1, 60176 Norrköping, Sweden \\ ${ }^{6}$ Finnish Meteorological Institute (FMI), P.O. Box 503, 00101 Helsinki, Finland
}

Received: 29 February 2008 - Published in Atmos. Chem. Phys. Discuss.: 8 May 2008

Revised: 26 January 2009 - Accepted: 26 January 2009 - Published: 5 March 2009

\begin{abstract}
The Satellite Application Facility on Climate Monitoring (CM-SAF) aims at the provision of satellitederived geophysical parameter data sets suitable for climate monitoring. CM-SAF provides climatologies for Essential Climate Variables (ECV), as required by the Global Climate Observing System implementation plan in support of the UNFCCC. Several cloud parameters, surface albedo, radiation fluxes at the top of the atmosphere and at the surface as well as atmospheric temperature and humidity products form a sound basis for climate monitoring of the atmosphere. The products are categorized in monitoring data sets obtained in near real time and data sets based on carefully intercalibrated radiances. The CM-SAF products are derived from several instruments on-board operational satellites in geostationary and polar orbit as the Meteosat and NOAA satellites, respectively. The existing data sets will be continued using data from the instruments on-board the new joint NOAA/EUMETSAT Meteorological Operational Polar satellite. The products have mostly been validated against several ground-based data sets both in situ and remotely sensed. The accomplished accuracy for products derived in near real time is sufficient to monitor variability on diurnal and seasonal scales. The demands on accuracy increase the longer the considered time scale is. Thus, interannual variability or trends can only be assessed if the sensor
\end{abstract}

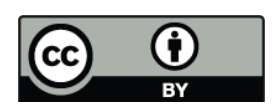

Correspondence to: J. Schulz (joerg.schulz@dwd.de) data are corrected for jumps created by instrument changes on successive satellites and more subtle effects like instrument and orbit drift and also changes to the spectral response function of an instrument. Thus, a central goal of the recently started Continuous Development and Operations Phase of the CM-SAF (2007-2012) is to further improve all CM-SAF data products to a quality level that allows for studies of interannual variability.

\section{Introduction}

Concerns about the Earth's climate implicate an increasing necessity for climate monitoring on a global scale. Climate change and variation occur on different time scales and data sets useful for climate monitoring must therefore cover longer time series to understand these changes. The demands on the accuracy increase accordingly to the time scales considered. At the seasonal to interannual time scale the accuracy requirements increase dramatically because climate phenomena at this scale are initiated by very small changes in the observed parameters. At decennial to centennial time scales which are exclusively suitable for trend detection the accuracy of data sets must be one order of magnitude higher than compared to the needs of detecting interannual fluctuations.

Only space-based observations can deliver the needed global coverage with sufficient quality and timeliness. Particularly over the ocean and sparsely populated areas satellite

Published by Copernicus Publications on behalf of the European Geosciences Union. 
data are largely the only data source. Existing satellites now provide sufficiently long data series that have been used for climate analysis (e.g., Santer et al., 2007, Mieruch et al., 2008 and Trenberth et al., 2005). Satellite data provide information on the climate system that are not available or difficult to measure from the Earths surface like top of atmosphere radiation, cloud properties or humidity in the upper atmosphere the two latter having a large impact on the greenhouse effect.

Understanding the processes which control the natural stability and variability of the climate system is one of the most difficult and challenging scientific problems faced by the climate science community today. An improved understanding of the interaction processes between water vapor and clouds as well as their radiative impact is urgently required.

The Earth's Radiation Budget (ERB) is the balance between the incoming radiation from the sun and the outgoing reflected and scattered solar radiation plus the thermal infrared emission to space. Earth surface conditions greatly influence the radiation budget, e.g. through surface temperature variations in the thermal infrared and through a critical contribution to the planetary albedo (especially for desert regions and snow- and ice-covered polar regions).

Water vapor is a major greenhouse gas and is usually considered to play an amplifying role in global warming through a strongly positive climate feedback loop (Held and Soden, 2000), although with some remaining question marks concerning the link to cloud feedback processes. Due to the non linearity of interactions of the radiation field and the water vapor, outgoing longwave radiation (OLR) is more sensitive to a small humidity perturbation in a dry environment than in a moist region. For instance, increasing the upper tropospheric humidity from $5 \%$ to $10 \%$ at constant temperature, increases the outgoing longwave radiation by $10 \mathrm{Wm}^{-2}$ while increasing the upper tropospheric humidity from $25 \%$ to $30 \%$ only modifies OLR by less than $5 \mathrm{Wm}^{-2}$. This confers a central role to the dry upper troposphere regions in the radiation budget and its sensitivity. Documenting the recent decades history of the water vapor field should give some understanding of the mechanisms at play in the climate and how it responds to the increasing greenhouse gas concentration. For instance, a potential drying of the upper troposphere as a consequence of a $\mathrm{CO}_{2}$ increase as postulated in recent climate change theory can be investigated with an extensive documentation of the tropospheric humidity from satellite (Rind, 1998; Soden, 2000).

Because the water vapor distribution results from the large scale dynamics and associated transports that take place at synoptic scales, its documentation can also yield some insights into the dynamics of the atmosphere and its evolution. It is then important to monitor its evolution with high temporal resolution over a long time period. This effort could in principle be useful to detect, if any, trends not only in the mean climate but also in the transient activity, which is central to the energy cycle.
Clouds exert a blanketing effect similar to that of water vapor. In the infrared spectral region clouds behave like black-bodies, and emit radiation back to the Earth and to outer space depending on their temperature. As water vapor, clouds absorb and emit infrared radiation and thus contribute to the warming of the Earth's surface. However, this effect is counterbalanced by the reflectance of clouds, which reduces the amount of incoming solar radiation at the Earth's surface. Because most clouds are bright reflectors they block much of the incoming solar radiation and reflect it back to space before it can be absorbed by the Earth surface or the atmosphere, which has a cooling effect on the climate system. The net average effect of the Earth's cloud cover in the present climate is a slight cooling because the reflection of radiation more than compensates for the greenhouse effect of clouds.

One of the most problematic issues in studying clouds is their transient nature- they are continuously changing in space and time, which make them very difficult to both observe and simulate in models. This also explains why differences in cloud descriptions and cloud parameterizations between various climate models are responsible for a major part of the variation seen in climate model scenarios through cloud feedback processes (Stephens, 2005). Hence, progress is needed here both concerning cloud observation and cloud modeling aspects.

From the above paragraphs it is obvious that a high quality combined water vapor - cloud - radiation time series derived from satellite data is of enormous value for climate research. This is reflected in the choice of products of the Satellite Application Facility (SAF) on Climate Monitoring (CM-SAF). The CM-SAF is part of EUMETSAT's SAF Network, that comprises eight SAFs (see www.eumetsat.int for further details). The SAF network is a network of networks, dedicated to tackle the tasks and challenges in the field of meteorology and climatology supported by satellite data as the main input. The CM-SAF as part of this network plays a major role in EUMETSAT's activities towards climate monitoring.

Beside the issues of monitoring and understanding the climate system, adaptation to and active protection against climate change is highly relevant to societies. Both are strongly coupled to the production of electricity, where solar energy systems provide a sustainable and environmentally sound alternative to traditional power plants. Accurate solar irradiance data is needed for the efficient planning and design of solar energy systems. CM-SAF radiation data may help to increase the efficiency of such systems which leads to a potential reduction of $\mathrm{CO}_{2}$ emissions by the replacement of fossil power plants.

This paper introduces the CM-SAF concept, its current products including their quality and its near future plan. Within the next section the historic background and the objectives of CM-SAF are described in more detail. This is followed by a description of the individual climate monitoring products including the techniques to derive them and 
estimations of achieved accuracy. The last section is dedicated to the tasks of the so called Continuous Development and Operations Phase (CDOP) with a duration of five years (2007-2012).

\section{Background and objectives}

First attempts to generate long-term data series of atmospheric quantities derived from satellite measurements go back to the early eighties when the International Satellite Cloud Climatology Project (ISCCP) started its work (Rossow and Garder, 1993). The cloud information from the ISCCP data set was successfully used to derive a climatology of the shortwave radiation budget (Gupta et al., 1999). Precursory cloud data sets are e.g., the PATMOS data set (Jacobowitz et al., 2003), the SCANDIA cloud climatology (Karlsson, 2003) over Scandinavia, and the European Cloud Climatology (Meerkötter et al., 2004) which were all derived from Advanced Very High Resolution Radiometer (AVHRR) observations. SCANDIA has recently been used to elucidate possible weaknesses of regional climate simulations with respect to the simulation of cloud amount, cloud optical thickness and the vertical distribution of clouds (Karlsson et al., 2008). The NASA Water Vapor Project (NVAP) provides global total column water vapor data sets derived from Television and Infrared Operational Satellite (TIROS) Operational Vertical Sounders (TOVS), and Special Sensor Microwave/Imager (SSM/I) data spanning a period over 14 years (1998-2001) (Vonder Haar, 2003).

Although accuracy and precision of satellite-based time series may locally be lower than existing and corresponding data sets derived from ground-based measurements, they provide a much more homogeneous data quality compared to the heterogeneous observation system at the ground. However, dedicated effort is needed to generate homogeneous, stable and accurate data sets with high spatial resolution from recent, current and future satellite sensors. Then, such time series of satellite-derived quantities can be used e.g., for the detection of climate change. Following the terminology of the NOAA White Paper on creating Climate Data Records (CDRs) from satellite measurements (Colton et al., 2003), CM-SAF has the mandate to generate thematic climate data records in an operational off-line environment. Environmental Data Records (EDR) are obtained if satellite sensor data are converted to geophysical variables in real time using the nominal calibration over time. EDRs may be aggregated to monthly means and used for some monitoring purposes. For a CDR usable for analysis of interannual variability or trends it is required to improve the calibration, to homogenise the series of data coming from different satellites, and to use only one retrieval scheme for the whole temporal record. The concept of different data records as used within NOAA and CMSAF is explained in more detail in Robinson et al. (2004).
A very accurate absolute calibration as well as a very high sensor stability over time is required to accomplish the needed product accuracy (Ohring et al., 2005). Additionally, radiance data coming from different satellite platforms must be intercalibrated. It is required that this data sets and related methods are provided by several satellite operators.

Within the range of essential climate variables (ECV) as defined in the GCOS Second Adequacy Report (GCOS, 2003) the CM-SAF currently focuses on the provision of geophysical parameters describing elements of the energy and water cycle. CM-SAF provides regional products with comparably high spatial resolution as well as global products that complement ongoing international activities. CMSAF exploits the polar orbiting NOAA and MetOp satellites utilizing data from the Advanced Very High Resolution Radiometer (AVHRR), High resolution Infrared Radiation Sounder (HIRS), Infrared Atmospheric Sounding Interferometer (IASI), Advanced Microwave Sounding Unit (AMSU) and Microwave Humidity Sounder (MHS) instruments. Additionally, the Global Earth Radiation Budget (GERB) (Harries et al., 2005) and the Spinning Enhanced Visible and Infrared Imager (SEVIRI) radiometers (Schmetz et al., 2002) on-board the METEOSAT Second Generation (MSG) satellites are used. Data from the Clouds and Earth's Radiant Energy System (CERES) on-board TERRA and AQUA support the retrieval of radiation fluxes at top of the atmosphere. Furthermore, data of the Special Sensor Microwave/Imager (SSM/I) series are used to provide a consistent time series of total column water vapor over the ocean spanning the period 1987-2005.

CM-SAF data sets can be categorized into three different groups fulfilling different requirements. During the Initial Operations Phase (IOP, 2004-2007) operational procedures to quickly process large amounts of data were established. Products are available in almost real time but retrieval schemes changed over time. Additionally, radiances used as input were only nominally calibrated, i.e., no intercalibration accounts for sensor changes and other sensor related errors. During the so called Continuous Development and Operations phase (CDOP, 2007-2012) the focus is on the generation of long homogeneous time series of the CM-SAF products. The three data set categories and their properties are:

- CDRs for operational climate monitoring are constructed from so called Environmental Data Records (EDR). EDRs are instantaneous estimates of geophysical variables retrieved in near real-time only utilizing information from the past and aiming at a small random error. Input to this processing are nominal calibrated radiances or automatically intercalibrated sensor data if provided by the space agencies. The instantaneous EDRs are then integrated over time to obtain daily and monthly averaged products. Within this process also information from the future is used, e.g., a whole month of data is used to compute daily averages 
for a particular month employing also temporal correlations to fill gaps. The application area of these data sets is on diurnal and sub-seasonal to seasonal time scales, e.g., the monitoring of extreme events and the support of NMSs climate departments in early dissemination of climate information to the public. Additionally, the products are accurate enough to be used for solar energy applications. The use on longer time scales depends on the quality of automated intersensor calibration. Derived geophysical averages may have to be corrected using ground based information for further use. The data sets currently created at CM-SAF mostly belong to this category.

- Reprocessed CDRs form a second class and will be created if substantial knowledge on the correction of instrument and retrieval errors can be applied. This should at least include inter satellite homogenisation and no algorithm changes over time for the production of the data set. Depending on the number of satellite instruments involved in a product and the success of automated radiance homogenisation as well as corrections of systematic errors caused by instrument failures or orbit variations, the products are expected to be useful for time scales ranging from diurnal, seasonal to inter-annual. For the latter scale the variability is much smaller compared to diurnal and sub-seasonal fluctuations. Most of the CM-SAF products will reach this status during the CDOP.

- A third class of CDRs will be provided for the analyses of long term climate variability (decadal). Here it is necessary that expert teams have improved absolute calibration of the involved instruments to the highest possible level and that other instrument and orbit related systematic errors are diminished to a level that the very small decadal variability in a variable can be monitored. Some of the parameters, e.g., total column water vapor over oceans from passive microwave imager data may reach this status shortly after the CDOP when the time series of such data approaches 30 years. Additionally, the records started from new instruments as IASI and others on EUMETSAT MetOp satellite are expected to deliver such high quality data to create a data set suitable for the analysis of decadal variability.

\section{Products, retrieval schemes and validation}

As mentioned above CM-SAF focuses on retrieving geophysical parameters from satellite data employing inversion schemes based on radiation transfer theory. This complements other international activities on the use of satellite data in climate research as the use of radiance data for climate trend detection and the assimilation of satellite data into dy- namical models to retrieve geophysical products as e.g. in the ERA-40 reanalysis. The products currently are:

- Cloud parameters: cloud fractional cover (CFC), cloud type (CTY), cloud top pressure (CTP), cloud top height $(\mathrm{CTH})$, cloud top temperature (CTT), cloud phase (CPH), cloud optical thickness (COT), cloud water path (CWP);

- Radiation budget parameters at the surface and the top of the atmosphere (TOA). Surface: Incoming shortwave radiation (SIS), surface albedo (SAL), net shortwave radiation (SNS), netlongwave radiation (SNL), downward (SDL) and outgoing longwave radiation (SOL), surface radiation budget (SRB); TOA: Incoming solar radiative flux (TIS), reflected solar radiative flux (TRS), emitted thermal radiative flux (TET);

- Humidity products: Total (HTW - surface to $100 \mathrm{hPa}$ ) and layered (HLW) precipitable water, mean temperature, and relative humidity for 5 layers $(1000-$ $850 \mathrm{hPa}, \quad 850-700 \mathrm{hPa}, \quad 700-500 \mathrm{hPa}, \quad 500-300 \mathrm{hPa}$, $300-200 \mathrm{hPa}$ ) as well as specific humidity and temperature at the six layer boundaries (HSH).

These products were mainly discussed and defined during the development phase of the CM-SAF (Woick et al., 2002). The list of products reflects atmospheric parameters that can be derived from sensors on-board operational satellites with state-of-the-art retrieval schemes. The list was confirmed by a user survey held by CM-SAF in 2001 which allowed also to prioritize the development of products. The majority of products is classified as essential climate variable (ECV), as can be seen in the GCOS implementation plan (GCOS, 2004). Although well known parameters as sea and land surface temperature as well as ice and snow cover are not explicitly provided their impact is implicitly covered by surface albedo and surface radiation fluxes. All products are available via electronic ordering at www.cmsaf.eu.

Currently, all CM-SAF products derived from instruments on the Meteosat platform cover the full METEOSAT visible disc. Products derived from AVHRR measurements cover an area between $30^{\circ} \mathrm{N}$ to $80^{\circ} \mathrm{N}$ and $60^{\circ} \mathrm{W}$ to $60^{\circ} \mathrm{E}$, i.e. basically Europe and the Northeast Atlantic. Water vapor products derived from ATOVS data are provided with global coverage. Near real time monitoring products are available from May 2007 onwards.

Additionally, a total column water vapor product derived from SSM/I data that covers global ice-free ocean areas is provided. The SSM/I record is based on homogenised SSM/I brightness temperatures (Andersson et al., 2009) and is available for the period July 1987 - August 2006. Cloud products and surface albedo will be further extended to cover the Inner Arctic. AVHRR, ATOVS and IASI data from the MetOp satellite will be used to further improve coverage and accuracy of the products in the near future. 
Table 1. Overview on CM-SAF product properties. CDR classes belong to those introduced in Sect. 2. Spatial resolution is given in km ${ }^{2}$ for products on equal area grids, others are on latitude/longitude grids. Codes for temporal resolution are: $\mathrm{M}=$ monthly mean, $\mathrm{D}=\mathrm{daily}$ mean, $\mathrm{MDC}=$ monthly diurnal cycle (hourly values averaged over the month).

\begin{tabular}{|c|c|c|c|}
\hline Product group (CDR class) & Product & Sensor, area and length of record & Spatial and Temporal Resolution \\
\hline Cloud parameter (I) & $\begin{array}{l}\text { CFC } \\
\text { CTY } \\
\text { CTP } \\
\text { CTH } \\
\text { CTT } \\
\text { CPH } \\
\text { COT } \\
\text { CWP }\end{array}$ & $\begin{array}{l}\text { AVHRR: Baseline / 01.11.2004- } \\
\text { AVHRR: Arctic / 01.01.2009- } \\
\text { SEVIRI: Meteosat disc / 01.09.2005 - }\end{array}$ & $\begin{array}{l}\text { AVHRR: }(15 \mathrm{~km})^{2}, \mathrm{M}, \mathrm{D} \\
\text { SEVIRI: }(15 \mathrm{~km})^{2}, \mathrm{M}, \mathrm{D}, \mathrm{MDC}\end{array}$ \\
\hline Humidity products (I) & $\begin{array}{l}\text { HTW } \\
\text { HLW } \\
\text { HSH }\end{array}$ & ATOVS: global / 01.01.2004 - & $(90 \mathrm{~km})^{2}, \mathrm{M}, \mathrm{D}$ \\
\hline Humidity products (II) & HTW & $\begin{array}{l}\text { SSM/I: global (ice free ocean) / } \\
01.08 .1987-31.08 .2006\end{array}$ & $\left(0.5^{\circ}\right)^{2}, \mathrm{M}, \mathrm{D}$ \\
\hline Surface radiation $(\mathrm{I})$ & $\begin{array}{l}\text { SIS } \\
\text { SAL } \\
\text { SNS } \\
\text { SDL } \\
\text { SOL } \\
\text { SNL } \\
\text { SRB }\end{array}$ & $\begin{array}{l}\text { AVHRR: Baseline / 01.11.2004 - } \\
\text { AVHRR: Arctic (only SAL) / 01.01.2009 - } \\
\text { SEVIRI: Meteosat disc / 01.09.2005 - } \\
\text { AVHRR-SEVIRI merged product: } \\
\text { Baseline and Meteosat disc / 01.05.2007 - }\end{array}$ & $\begin{array}{l}\text { AVHRR: }(15 \mathrm{~km})^{2}, \mathrm{M}, \mathrm{D} \\
\text { SEVIRI: }(15 \mathrm{~km})^{2}, \mathrm{M}, \mathrm{D}, \mathrm{MDC} \\
\text { AVHRR-SEVIRI: }(15 \mathrm{~km})^{2}, \mathrm{M}\end{array}$ \\
\hline Top of atm. radiation (I) & $\begin{array}{l}\text { TIS } \\
\text { TRS } \\
\text { TET }\end{array}$ & $\begin{array}{l}\text { DIARAD/VIRGO / 01.02.2004 - } \\
\text { GERB and CERES (merged dataset) } \\
\text { Meteosat disc, 01.02.2004 - }\end{array}$ & $(45 \mathrm{~km})^{2}, \mathrm{M}, \mathrm{D}, \mathrm{MDC}$ \\
\hline
\end{tabular}

Most of the CM-SAF products are provided at a $(15 \mathrm{~km})^{2}$ spatial resolution, with the exception of the top of the atmosphere radiation and water vapor products from infrared and microwave sounders, which are available at $(45 \mathrm{~km})^{2}$ and $(90 \mathrm{~km})^{2}$ resolution, respectively. The mean diurnal cycle is also provided for some of the products based on SEVIRI and GERB data. Accuracy requirements for near real time monitoring products are relaxed relative to the accuracy requirements formulated by Ohring et al. (2005). Instead they are more oriented towards the limits that can be reached by current satellite observations.

Although cloud products and surface radiation fluxes are derived independently from AVHRR and SEVIRI radiances, merged products are optionally provided for selected radiation fluxes. The merging is performed at the level of monthly mean products on the product grid $(15 \mathrm{~km})^{2}$. Due to lower temporal sampling of AVHRR south of $55^{\circ} \mathrm{N}$ the accuracy of monthly means is less compared to SEVIRI estimates. North of $55^{\circ} \mathrm{N}$ the accuracy of SEVIRI estimates is decreasing be- cause of the larger viewing angles. Thus, a simple linear average for radiation fluxes in a latitude band between $55^{\circ} \mathrm{N}$ and $65^{\circ} \mathrm{N}$ (SEVIRI results gradually replaced by AVHRR results) is computed to merge both products together. Merged cloud products are not defined due to problems of efficiently taking into account the large spatial and temporal sampling differences and the different instrument characteristics.

Table 1 gives an overview on the CM-SAF products including the corresponding CDR class, product name, sensor and record length, spatial and temporal resolutions. Currently, all CM-SAF products belong to the CDR class I with the exception of SSM/I-derived total column water vapor which is a CDR-II product.

Within this section the used retrieval schemes, validation activities and example products are introduced. Many of the CM-SAF products require information on cloud cover, e.g., if a pixel is cloudy or cloud free. Thus, we start with the description of methods used for cloud property retrieval. This is followed by a description of the water vapor products. 
Finally, retrieval schemes for the resulting radiation fluxes at the top of the atmosphere and the surface are explained and their quality is assessed.

\subsection{Cloud properties}

All cloud parameters mentioned above are derived from both NOAA/AVHRR and MSG/SEVIRI visible and infrared channels, with corresponding spatial and temporal sampling.

\subsubsection{Retrieval}

Fractional cloud cover, cloud type and cloud-top parameters are derived following Dybbroe et al. (2005a), Dybbroe et al. (2005b) for NOAA/AVHRR and Derrien and LeGléau (2005) for MSG/SEVIRI. Fundamental principles of the algorithms applied to SEVIRI raw data can already be found in an earlier paper by Derrien et al. (1993). The algorithms are provided by the SAF in Support to Nowcasting and Very Short-Range Forecasting (NWC-SAF). Both retrievals are based on a multi-spectral threshold technique applied to each pixel of a satellite scene. Typically, these methods allow to retrieve cloud parameters during daylight and during nighttime in the visible and near-infrared part of the spectrum between $0.5 \mu \mathrm{m}$ and $3.7 \mu \mathrm{m}$ and in the infrared region between 10 and $12 \mu \mathrm{m}$. The SEVIRI algorithm also makes use of the $8.7 \mu \mathrm{m}$ channel.

The first retrieved parameter is the fractional cloud cover based on cloud masking of several satellite pixels. The majority of threshold tests uses the infra-red channels of the radiometers, e.g. the well-known difference of brightness temperatures inside and outside the so-called infrared window channels to detect high-level cirrus clouds (split-window technique, see e.g. Inoue, 1987). The series of tests to be passed allows to finally separate clear-sky, cloudy and partially cloudy pixels. Also snow/ice-covered pixels and unclassified pixels (where all tests failed) are identified. A cloud-mask is then generated for the entire SEVIRI slot or AVHRR orbit which is used in subsequent algorithm steps, e.g. for the cloud-top parameter retrieval.

The first step for cloud type retrieval is to use measured cloud temperatures in the infrared channels to separate thick clouds. For further separation of water clouds and semitransparent ice clouds, differences in reflection characteristics at short-wave infrared channels (e.g. at 1.6, 3.7 and $3.9 \mu \mathrm{m})$ and differences in transmission characteristics in infrared channels (3.7 or $3.9 \mu \mathrm{m}, 8.7,11$ and $12 \mu \mathrm{m}$ ) are utilized.

Cloud-top pressure assignment for MSG/SEVIRI cloudy pixels follows Schmetz et al. (1993) and Menzel et al. (1983), respectively. These methods rely on the linear relationship between radiances in one window channel and in one sounding channel and are used to estimate the cloud top. The cloud top products are to some extent influenced by potential errors in the used background temperature profiles from meteoro- logical analysis as provided by the GME model. The model is described in Majewski et al. (2002). However, for climate monitoring purposes we believe that the current methodology is better than to rely on standard climatological profiles which would preclude or at least complicate future trend analysis. This concerns especially the planned historic processing efforts in the CM-SAF where the GME model analysis will be replaced by well established model re-analysis in order to constrain and limit the impact from errors in the used background fields.

Besides the macrophysical cloud properties, the CM-SAF provides cloud physical properties which are cloud phase, cloud optical thickness, and the cloud liquid water path. These properties are discussed in the following:

The AVHRR cloud phase product is based on a pure temperature interpretation using $11 \mu \mathrm{m}$ channel brightness temperatures, as suggested by Rossow and Schiffer (1991). For the SEVIRI-based cloud phase product we compare simulated (precalculated and stored in look-up table) and measured reflectances of the $1.6 \mu \mathrm{m}$ SEVIRI channel which is suited to distinguish water clouds from ice clouds (Jolivet and Feijt, 2003). Radiative transfer simulations are performed using the Doubling Adding KNMI (DAK) model (Haan et al., 1987). Once the initial cloud phase is retrieved, an additional $10.8 \mu \mathrm{m}$ cloud top temperature threshold test determines the final cloud phase, which maintains the initial retrieval as ice phase if the cloud-top temperature is below 265K (Wolters et al., 2008).

The cloud-optical thickness is calculated following the method described in Nakajima and King (1990). This method relies on the fact that the top of atmosphere reflectance at a non-absorbing visible spectral channel is mainly a function of the optical thickness, whereas the reflectance in a water or ice absorbing near-infrared spectral channel is mainly a function of the cloud particle size. An iteration algorithm is used to simultaneously retrieve cloud optical thickness and particle size from the measurements of both channels. Nakajima and Nakajima (1995) introduced such an algorithm for the $0.6 \mu \mathrm{m}, 3.7 \mu \mathrm{m}$, and $10 \mu \mathrm{m}$ AVHRR channels. Roebeling et al. (2006) successfully adapted their approach to SEVIRI measurements, but using the $1.6 \mu \mathrm{m}$ instead of the $3.7 \mu \mathrm{m}$ channel. The cloud liquid water path is calculated after Stephens et al. (1978). Note that reliance on visible and near-infrared channel data limits the availability of products to daytime conditions. Moreover, NOAA currently only operates the $1.6 \mu \mathrm{m}$ channel on the NOAA-17 satellite.

Daily mean cloud products are derived for pixels with at least six NOAA overpasses per day. Monthly products are subsequently calculated from daily averages, requiring at least twenty valid days per month. For SEVIRI-based products from Meteosat data those restrictions are only relevant in cases with substantial data loss. 


\subsubsection{Validation}

Validation of cloud coverage results derived from both AVHRR (locally over the baseline area) and the entire METEOSAT disk against ground-based synoptical observation showed that results typically agree within one octa cloudiness. The satellite observations tend to overestimate the cloud coverage over sea where contrasts between clouds and the ground are generally higher, both for the solar and the thermal spectral range. Furthermore, the SEVIRI-based retrieval overestimates the cloudiness at large observation angles while the opposite effect is observed over the tropical belt where observations are made in near-nadir viewing mode. Differences exceed in both cases $10 \%$.

On the basis of case studies, CM-SAF results for SEVIRI also were compared with results derived from Moderate Resolution Imaging Spectrometer (MODIS) and from CloudAerosol LIDAR with Orthogonal Polarization (CALIOP) observations. These comparisons confirmed the results described above. Further comparisons to MODIS are now done operationally. Results are published every year in the CMSAF Annual Validation Report.

The validation of the cloud type is based on temporally sampled radar profiles and radiosonde measurements at European measurement sites (Cabauw, The Netherlands; Chilbolton, UK) which were also involved in the CloudNET campaign (Illingworth et al., 2007). From these groundbased measurements we retrieve corresponding cloud-top pressure and cloud-top temperature which are subsequently compared to spatially sampled satellite-based results of $3 \times 3$ satellite pixels. The validation for mid-level clouds is very difficult as only very few match-ups have been found. Cloud type assignments are finally made for three cloud layers, i.e. low-level clouds, mid-level clouds, and high-level clouds. Best performance is found for low-level clouds which are consistently classified for $85 \%$ of pixels, followed by the comparably good classification of high-level clouds $(80 \%)$ and fair results for mid-level clouds (50\%).

Again radar and also lidar measurements are used to determine cloud-top parameters from ground-based measurements. There is however a lack of ground-based measurements to compare with and validation is an ongoing task. Generally, the methods (comparison of hourly results against temporally sampled lidar measurements and radar data) applied to opaque clouds have shown that satellite estimates are reasonable, although typically overestimating the cloud-top height, while results for semi-transparent clouds and multilayered scenes are usually of lower quality. We found an average bias of about $300 \mathrm{~m}$ for available measurements from the above-mentioned CloudNET sites.

Similarly, CloudNET data are used for the validation of the cloud phase product. For cloud scenes collocated and synchronized with ground-based observations accuracies are found better than $5 \%$ for cloud layers with optical thickness larger than $\sim 5$. In addition, both the ground-based observed monthly water and ice cloud occurrence is reproduced well by the cloud phase product, with bias errors mostly within $\pm 10 \%$ (Wolters et al., 2008).

The cloud-optical thickness is validated using groundbased pyranometer measurements of global irradiance. A direct relation between irradiance and COT is limited to fully overcast sky and homogeneous cloudiness (Boers et al., 2000). Also, the accuracy of the cloud-optical thickness product decreases at higher COT values (King, 1987) where the visible measurements show less sensitivity to COT values. Thus, a more recent approach from (Deneke et al., 2005) is applied which basically links satellite-derived COT to the atmospheric transmission for different atmospheric conditions. Then, deviations of ground-based and satellite-inferred transmission can be attributed to uncertainties in the retrieved COT. Since the cloud liquid water path (CWP) is calculated from atmospheric transmission and droplet effective radius information, errors of these quantities also affect the CWP retrieval.

The CWP retrievals are consequently less reliable for optically thick clouds $(\mathrm{COT}>70)$. In addition, due to the neglected three-dimensional structure of cloud fields the droplet effective radius and CWP of a single satellite pixel may be largely overestimated. Recent validation activities of CWP based on ground based microwave radiometer measurements indicated an absolute accuracy better than $5 \mathrm{gm}^{-2}$, which corresponds to relative accuracy better than $10 \%$ (Roebeling et al., 2008).

Monthly mean values (September, 2007) of the cloud-top temperature obtained from AVHRR and SEVIRI observations (Fig. 1) and the cloud liquid water path (Fig. 2) derived from METEOSAT-9/SEVIRI radiances are exemplarily shown for the CM-SAF baseline area and the full disc, respectively. We used High Resolution Picture Transmission (HRPT) AVHRR observations that were locally received at Offenbach/Germany $\left(50.1^{\circ} \mathrm{N}, 8.7^{\circ} \mathrm{E}\right)$. Thus, the area covered by AVHRR data is smaller in the east-west dimension but extends towards higher latitudes.

\subsection{Water vapor products}

The CM-SAF water vapor products are generated employing measurements from polar orbiting (NOAA and DMSP) platforms. The ATOVS suite of instruments (High Resolution Infrared Radiation Sounder - HIRS, Advanced Microwave Sounding Unit - AMSU) on NOAA and MetOp satellites, the SSM/I on the DMSP satellites represent different measurement principles over a large range of the electromagnetic spectrum. Each sensor has its individual strengths but also weaknesses, e.g., the SSM/I is providing highly accurate total column water vapor estimates but only over ice free oceans. The ATOVS suite of instruments is the only one that provides information on the vertical profile of temperature and water vapor over long time periods. The capability to retrieve profile information is very much enhanced from 2007 

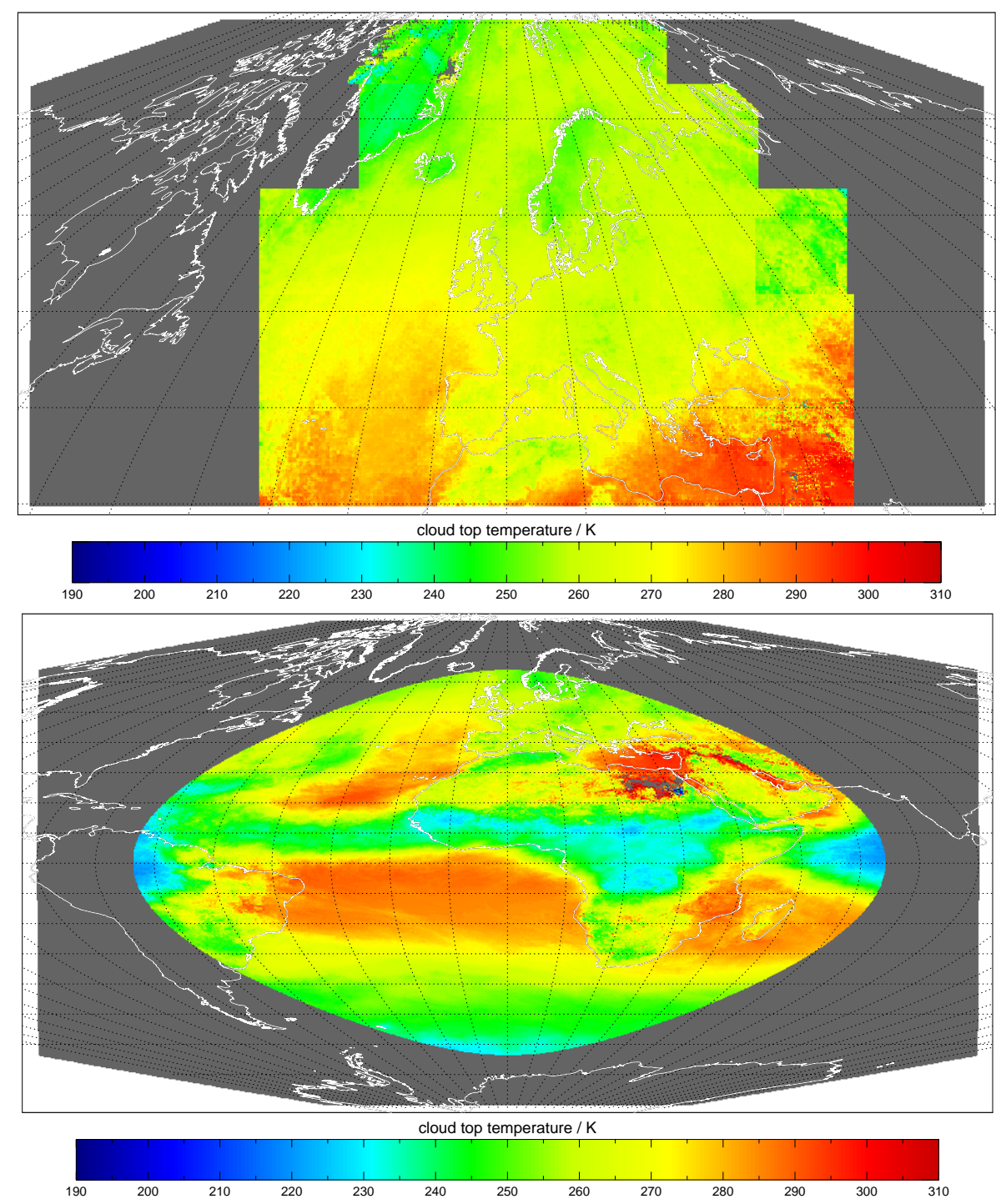

Fig. 1. Monthly mean cloud-top temperature for September 2007 derived from AVHRR observations (top panel) and from Meteosat9/SEVIRI (lower panel).

on since the IASI instrument is available. However, before a climate monitoring product can be designed using IASI measurements, the radiance records have to be consolidated and their errors be understood.

\subsubsection{Methodology}

Currently, CM-SAF is providing two products:

\section{ATOVS product}

Total column water vapor and integrated water vapor in five thick layers is provided (Table 1). Additionally, mean values for temperature and relative humidity w.r.t. water are provided for these layers. As an extra data set also the original retrieval of temperature and mixing ratio is available at the layer boundaries to eventually support water vapor transport calculations. This data set is produced in a near-real time mode to provide climate departments in National Meteorological Services with early data for their routine analysis. However, as inter satellite biases are not corrected automatically a reprocessing of the data back to the start of the ATOVS sensor suite in 1998 is envisaged.

The standard International ATOVS Processing Package (IAPP) is applied to ATOVS level 1c data and provides profiles of temperature and mixing ratio. Following the description of the retrieval algorithm in Li et al. (2000) a cloud detection and removal process is first applied to HIRS data to 


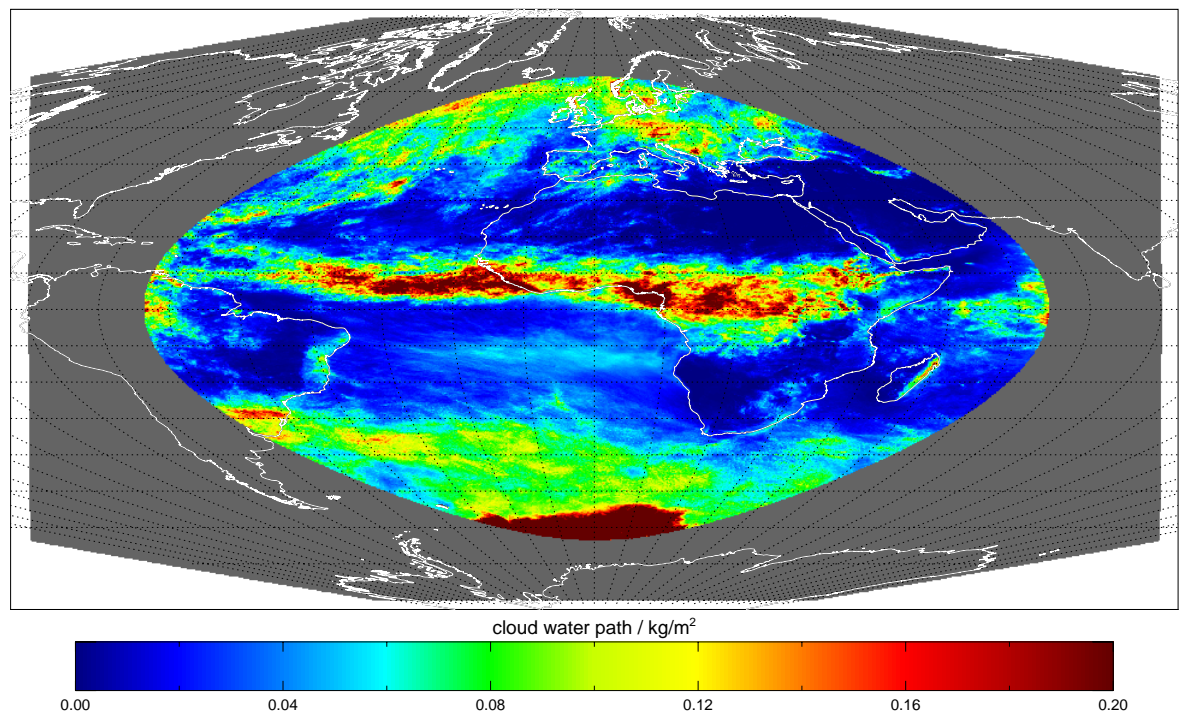

Fig. 2. Monthly mean cloud liquid water path for September 2007 derived from Meteosat-9/SEVIRI observations.

assure that only cloud-free HIRS pixels are used. A nonlinear iterative physical retrieval is used to derive the atmospheric profiles.

The needed first guess for such a retrieval can be provided by a statistical regression retrieval or a Numerical Weather Prediction (NWP) model first guess field. To keep consistency with the CM-SAF cloud and radiation flux products, NWP data from the German global model (GME) as described in Majewski et al. (2002) are used as first guess. This is favorable compared to the results of the regression retrieval as those contain a lot of artifacts over arid and semi-arid terrain and in mountainous regions. In order to assess the sensitivity of temperature and mixing ratio profiles to the first guess we compared the initial guess from GME with the corresponding instantaneously retrieved profiles from ATOVS observations. For this comparison we considered the mean absolute and the mean absolute relative difference for temperature and mixing ratio profiles, respectively. The normalisation is carried out with respect to the arithmetic mean of initial guess and instantaneous profile. The retrieval scheme changes the temperature profile from the initial guess on average by $0.6 \mathrm{~K}$ near the surface and by $1.1 \mathrm{~K}$ at $200 \mathrm{hPa}$. Standard deviations are $1.5 \mathrm{~K}$ near the surface and $2 \mathrm{~K}$ near $200 \mathrm{hPa}$. The maximum mixing ratio change occurs also at $200 \mathrm{hPa}(35 \%)$ and exhibits a near surface value of $12 \%$. The standard deviation for mixing ratio is relatively large and approximately of the same order as the mean absolute relative difference. The maximum change in the tropopause region is noteworthy due to its large relevance for climate in view of the radiative effect of water vapor at such levels.

The initialization with the GME model results has largest impact in the lower- to mid-troposphere $(900-700 \mathrm{hPa})$ as the profiles are not changed very much from the model fields. The consequences for a CDR class I data set are small as the resulting satellite product will only have major changes when the NWP model changes apruptly its description of the water vapor field which is not very likely. For further development into a CDR class II data set a NWP re-analysis has to be used to avoid spurious effects on longer term variability caused by model changes.

The main satellite data source for the retrieval process depends on the cloudiness of a scene and the underlying surface. Retrievals over oceans rely on all sensors whereas retrievals over land surfaces are mainly based on cloud-free HIRS measurements.

An example of ATOVS derived global monthly mean integrated water vapor content and corresponding extra daily standard deviation is shown in Fig. 3. Global fields are provided in Behrmann cylindrical equal area projection at a horizontal resolution of $(90 \mathrm{~km})^{2}$. The daily and monthly mean products are merged products derived from all available ATOVS sensors from NOAA 15, NOAA 16 and NOAA 18 platforms. The ATOVS system on MetOp will be added during 2008.

An objective analysis method (Kriging) is applied that provides a spatial distribution of mean values and their errors. Figure 4 shows the daily mean, its corresponding error and the number of independent measurements per day for the 8 September 2006. The number of independent measurements from satellites is rather given by the number of satellite overpasses because individual pixels cannot be treated as independent measurements (Lindau and Schulz, 2004). The field shows the typical sampling with polar orbiters during one day with data gaps in the subtropical regions. Those 
ATOVS Water Vapour Column 200609
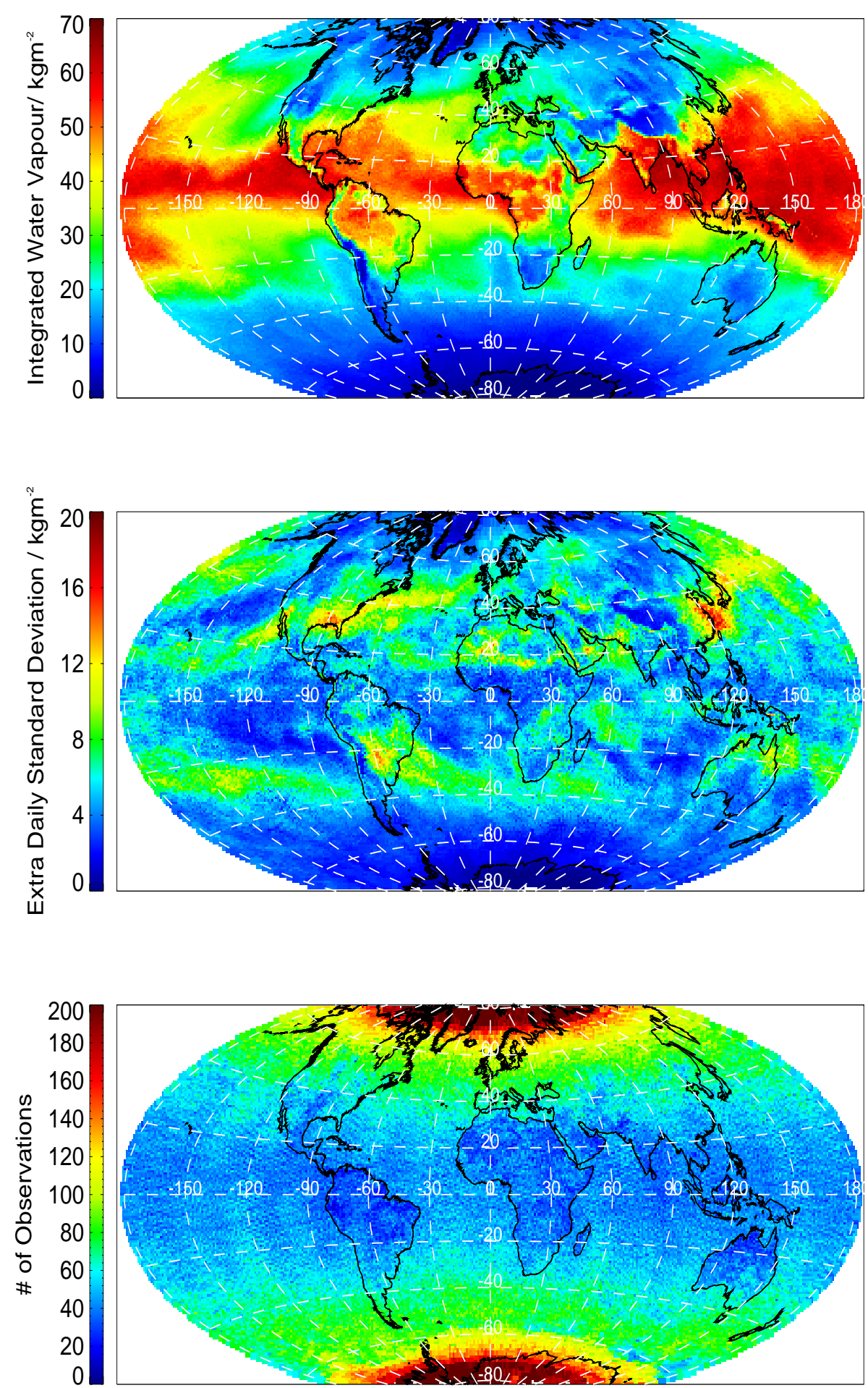

Fig. 3. Monthly mean vertically integrated water vapor (upper panel), corresponding extra daily standard deviation (middle panel) and number of independent observations (lower panel) derived from ATOVS data for September 2006. 
ATOVS Water Vapour Column 20060908
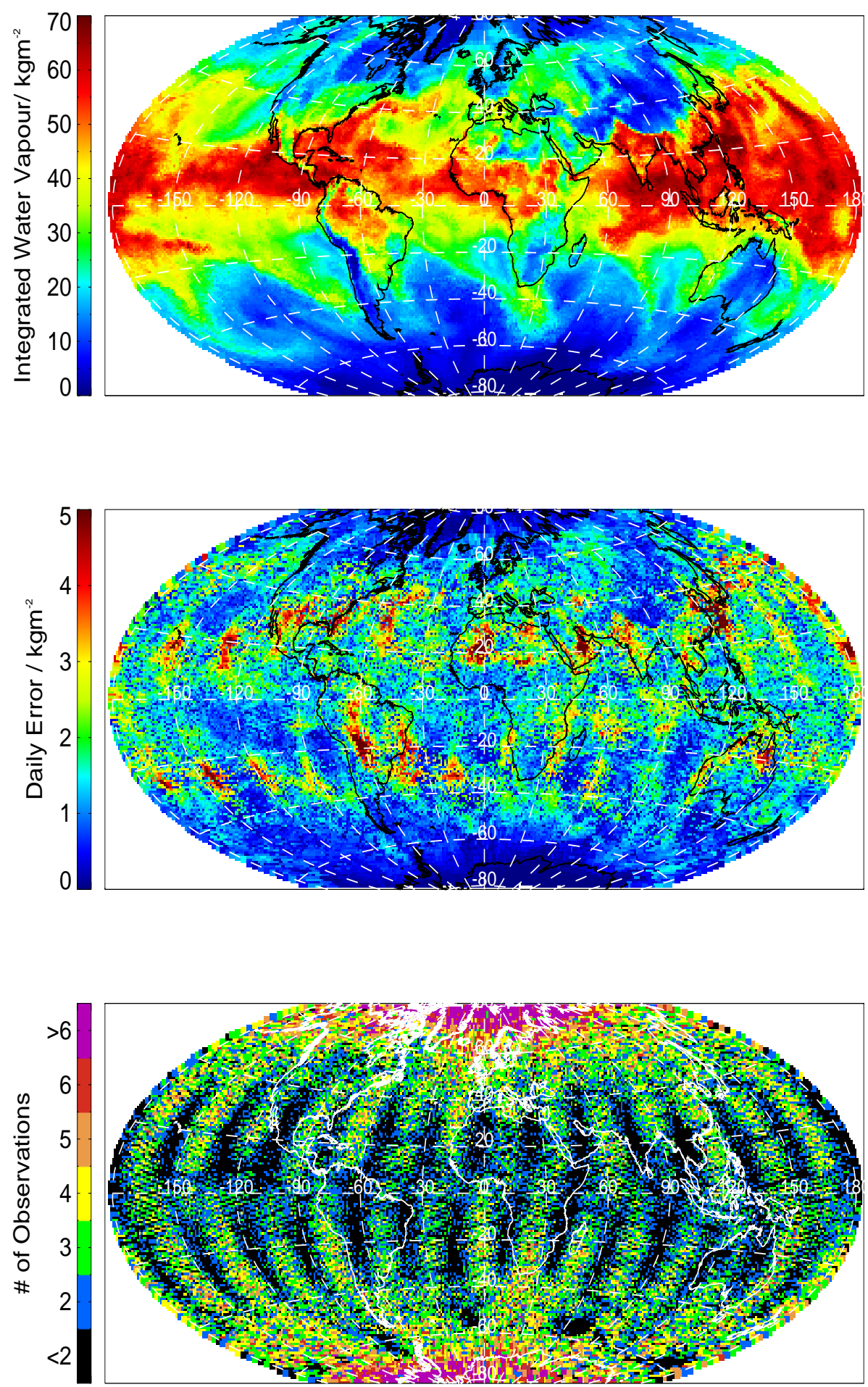

Fig. 4. Daily mean of vertically integrated water vapor (upper panel), daily error (middle panel) and number of independent observations (lower panel) derived from ATOVS data for 8 September 2006. 

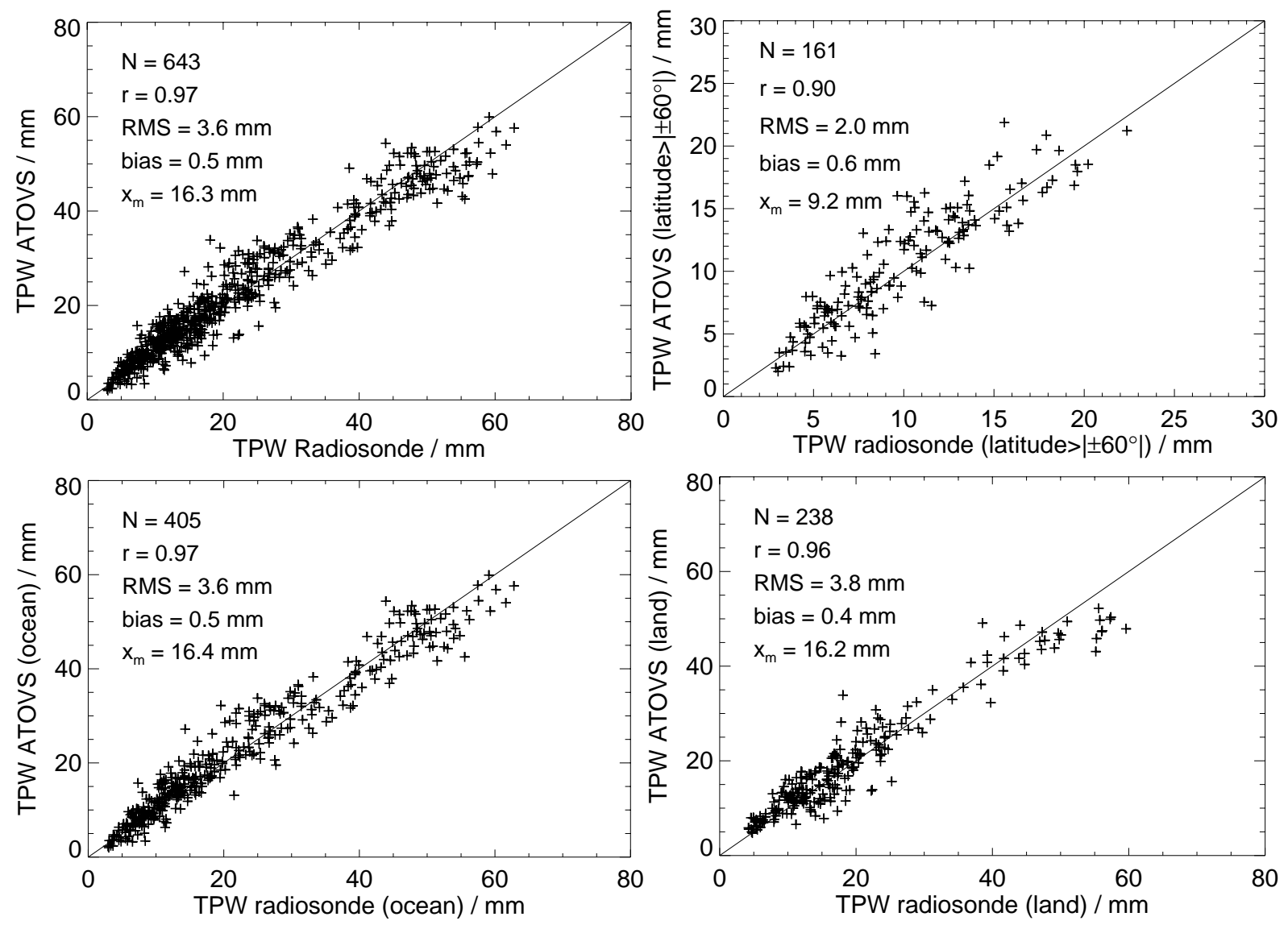

Fig. 5. Global comparison of daily averages of vertically integrated water vapor for October 2004: all data (top left), data north and south of $60^{\circ}$ latitude (top right), data over ocean (bottom left) and data over land (bottom right).

gaps are effectively interpolated in the daily mean field. The corresponding error field for this day represents larger errors where no measurements are available and where the intradaily variability is not well represented with $4-6$ satellite overpasses per day as over the Gulf Stream region east of the USA. Large errors appear also in places where it is expected that the retrieval is hindered by difficult surfaces as over the Sahara where knowledge of emissivity and the diurnal cycle of the surface temperature limit the quality of the retrieval. As the method is also capable of handling retrieval errors and error covariances an improved error budget calculation is under development and will further enhance the quality of the error map.

\section{SSM/I product}

A total column water vapor estimate over ice free oceans is derived from measurements of the SSM/I employing the retrieval by Schlüssel and Emery (1990). The above mentioned Kriging method is also used to combine the SSM/I measurements in an optimal way. The record covers the period 1987-2005 and is updated in yearly intervals. This data set can be regarded as a climate data set suitable for long term variability studies as all SSM/I radiometers have been intercalibrated using a statistical method described in Andersson et al. (2009).

\subsubsection{Validation}

\section{ATOVS product}

An initial validation of ATOVS results was performed for the period January 2004 to December 2005 employing radiosonde data recorded at 173 Global Climate Observing System Upper-Air Network (GUAN) stations. The radiosonde data are used to validate the ATOVS daily averages on the $(90 \mathrm{~km})^{2}$ grid. For this purpose the radiosonde data are allocated to the grid boxes and averaged over the day if more than one radiosonde ascent is available in a grid box. Note that a comparison to radiosonde data is more or less equivalent to a comparison of the products performance over land surfaces. Over ocean better results are expected because also the microwave instruments contribute to the product whereas over land it is mainly a HIRS product supported by the first 
guess of the retrieval. Additionally, the comparison is also slightly biased to the Northern Hemisphere as $56 \%$ of the GUAN stations are located there. On the Southern Hemisphere about $10 \%$ of the stations are located near the coast of Antarctica which is a very difficult environment for the satellite product.

As a quality measure for the comparison points we prescribed to have at least two radiosonde observations per day in an ATOVS product grid box because we compare daily mean values. This requirement reduces the total number of comparisons approximately by a factor of two compared to the existing radiosonde data.

The quality of radiosonde observations considerably varies among the different stations. Different calibration procedures and various ages of radiosondes can influence the quality of the measurements. The latter issue can have a large effect on the bias ranging from -4 to $-10 \%$ of relative humidity observations as shown by Miloshevich et al. (2004). In presence of ice saturation the bias largely increases. It is unclear which stations apply the proposed correction algorithm of (Miloshevich et al., 2004) in their routine observations as this is not part of the available radiosonde meta data. Smaller errors in radiosondes may be expected from the newly established GCOS Reference Upper-Air Network (GRUAN). GRUAN is required to measure temperature and humidity profiles with an accuracy of $0.1-0.2 \mathrm{~K}$ and $2 \%$, respectively GCOS (2007). It is expected that radiosonde observations distributed over the GTS does not have this quality.

As an example Fig. 5 shows four scatter plots for October 2004 indicating a very high Pearson product-moment correlation (0.94) between radiosondes and retrievals. The products exhibit a small bias and RMS of $0.5 \mathrm{~mm}$ and $3.6 \mathrm{~mm}$, respectively. In addition, scatter plots are shown separately for land and ocean stations as well as for stations in polar regions, i.e., lat $>\left| \pm 60^{\circ}\right|$. Ocean stations are stations within $50 \mathrm{~km}$ off the coast. No significant decrease or increase in quality between all, land and ocean stations becomes evident. Even in the problematic polar regions the ATOVS products exhibit high quality.

The time series of bias between ATOVS products and radiosonde observations is shown in Fig. 6. TPW shows an average bias of $0.4 \mathrm{~mm}$. The largest bias of the individual layers is found for layer 4 (LPW4), with a value of $0.8 \mathrm{~mm}$ in July 2005. All other layers have biases below $| \pm 0.3 \mathrm{~mm}|$, so that the TPW bias is dominated by the LPW4 bias.

A tendency for an annual cycle of TPW and LPW4 biases can be observed in Fig. 6, with a maximum during Northern Hemisphere summer months. More frequent radiosonde stations influenced by continental climate and a difference in temporal sampling of the diurnal cycle of precipitable water between ATOVS and radiosondes might cause the annual cycle of the bias. The time series separated in land an ocean actually shows that the annual cycle appears only over land. To really proof this seems beyond the scope of this paper.

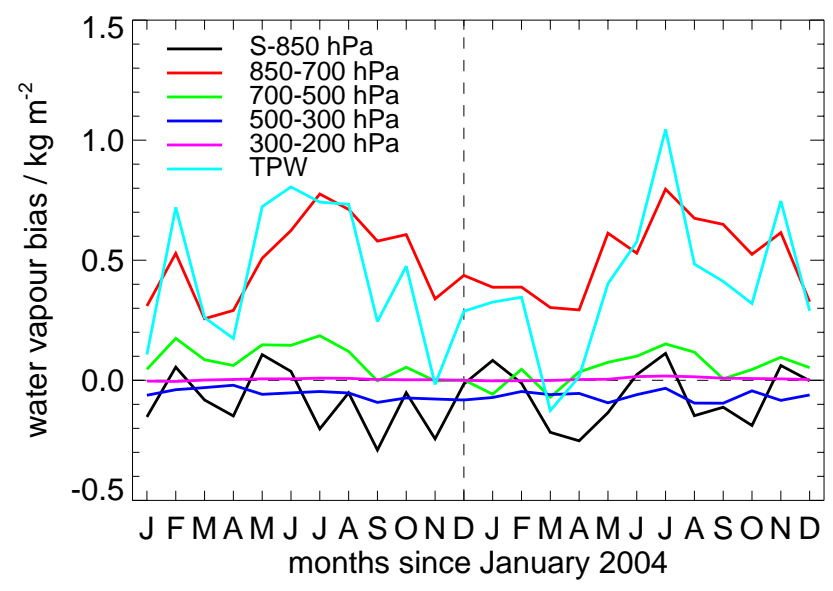

Fig. 6. Global mean bias for the total column and layered water vapor contents.

\section{SSM/I product}

Schlüssel and Emery (1990) did initial comparisons of instantaneous SSM/I total column water vapor retrievals to globally distributed radiosondes for data during July 1987. As collocation criteria they used matches within $\pm 3 \mathrm{~h}$ and $0.5^{\circ}$ latitude and longitude. The sample size was around 300 matches and the bias and rms errors are $0.3 \mathrm{~mm}$ and $5.6 \mathrm{~mm}$, respectively. This result was confirmed by (Schulz et al., 1993) who found $0.4 \mathrm{~mm}$ for the bias and $5.8 \mathrm{~mm}$ for the rms using also data from August 1987.

The most recent and comprehensive analysis of total column water vapor content retrievals from passive microwave imagers has been done by (Sohn and Smith, 2003). They compared five statistical (including the Schlüssel and Emery (1990) algorithm) and two physical algorithms in the framework of monthly and zonally averaged values. The global database of radiosondes used covered the period July 1987 to December 1990 (42 months). Statistics were derived from point pairings matched within $\pm 6 \mathrm{~h}$ and $60 \mathrm{~km}$. Most of the differences in bias and rms errors between the algorithms can be explained by different training data sets and different methods to exclude pixels with high liquid water paths or rain.

Considering regional differences between algorithms by comparing global monthly mean maps Sohn and Smith (2003) found that the Schlüssel and Emery (1990) is closest to the Wentz (1995) optimum statistical algorithm which had the best all around rms statistics. Maximum differences between these algorithms are $\pm 1.5 \mathrm{~mm}$ with well balanced positive-negative bias distribution.

Looking at zonally averaged water vapor contents (Fig. 12 in Sohn and Smith, 2003) it is striking that minimum and maximum excursions of the algorithms occur at equatorial, subtropical, and mid-latitude latitudes, not unlike the zonally 
averaged profiles of cloudiness and precipitation. Sohn and Smith (2003) used the original brightness temperature thresholds of the published algorithms to exclude precipitating pixels from the record. In the current software version used with CM-SAF this is not used. Instead precipitation and cloud liquid water path retrieved from SSM/I data are used to sort out pixels. From this one may expect that minimum and maximum excursion are smaller with the new version.

The evaluation of the SSM/I retrieval schemes in Sohn and Smith (2003) has shown that the current CM-SAF scheme is fully competitive compared to other existing retrievals. The presented comparison results from Sohn and Smith (2003) are based on SSM/I data from the DMSP F8 and F10 platforms that need substantial corrections because of a nonfunctioning $85 \mathrm{GHz}$ channel on F8 and large height and therefore zenith angle variations of the F10 satellite. It is not described if those features are corrected in the data used in the Sohn and Smith study. Thus, the there found bias errors can be caused by a missing correction for those effects. However, the comparison statistics also show that the SSM/I is clearly the best suitable instrument for climate monitoring of vertically integrated water vapor over oceans.

\subsection{Top of atmosphere radiation fluxes}

Top of the atmosphere radiation fluxes can principally be used for the evaluation of the radiative budget of climate models and reanalysis. The temporal resolution of the geostationary satellite data $(15 \mathrm{~min})$ matches reasonably well with the time step of current global models and processes like convection and surface heating may be studied on a model time step basis. The radiative fluxes at the top of the atmosphere depend mainly on the presence of clouds, while cloud information is not directly assimilated into atmospheric models. The comparison of the radiative fluxes as calculated by the model and as measured from satellites provides a quality control of the model cloud parameterizations and/or the model cloud radiative properties, see e.g., Allan et al. (2007).

Throughout this chapter reflected solar radiation with wavelengths roughly below $4 \mu \mathrm{m}$, will be referred to as shortwave broadband radiation. Emitted thermal radiation with wavelengths roughly above $4 \mu \mathrm{m}$, will be referred to as longwave broadband radiation. The term narrowband radiation will be used to refer to the measurement by individual channels of a multi-spectral imager.

Products as clear sky flux or cloud radiative forcing that are derived products based on the existing basic products of the radiative fluxes at the top of the atmosphere and of the cloud properties are planned for inclusion in the CM-SAF product suite until 2012.

\subsubsection{Retrieval}

The individual single satellite products from GERB and CERES on-board the AQUA and TERRA satellites are de- rived from the basic radiance measurements of the instruments. The CM-SAF top of atmosphere radiative flux products are merged from the individual satellite products of GERB and CERES (see Harries et al., 2005 for details). In that sense these products are level 3 products. The incoming solar radiative flux is determined from the Differential $\mathrm{Ab}-$ solute Radiometer DIARAD on-board the SOlar and Heliospheric Observatory (SOHO) satellite (Dewitte et al., 2004).

CM-SAF top of atmosphere radiative fluxes are available with high temporal and spatial resolution covering the full Meteosat disc and polar latitudes. On the Meteosat disc GERB measurements are used to benefit from its high temporal resolution. CERES measurements are exclusively used over polar regions with improved temporal sampling where GERB measurements are not available. GERB results are compared with CERES data in the solar spectral range to verify if measurements suffer from systematic Angular Dependency Model (ADM) errors. While empirical ADMs are derived from the CERES instrument on the Tropical Rainfall Measurement Mission (TRMM) satellite using the Visible and InfraRed Scanner (VIRS) imager for scene identification (Loeb et al., 2003), the longwave model stems from theoretical considerations based on radiative transfer calculations (Clerbaux et al., 2003).

Example products are shown in Fig. 7 where the monthly mean top of atmosphere thermal emitted flux and the solar reflected flux are given for June 2007. The high values of the reflected solar radiation and the low values of the emitted thermal radiation around the equator are due to the abundance of deep convective clouds in the tropical convergence zone associated with the rising branch of the Hadley circulation. Since in the tropical convergence zone the reflected solar radiation is dominated by the presence of clouds, there is little land-ocean contrast. To the contrary, for the region around the Sahara and Saudi Arabia, clear sky conditions occur frequently due to the large scale subsidence associated with the descending branch of the Hadley circulation. Therefore in the subsidence region, the reflected solar radiation is determined by the surface albedo, and there is a high landocean contrast due to the high albedo of the desert, and the low albedo of the ocean.

\subsubsection{Validation}

The accuracy of the incoming solar flux product is dominated by the accuracy of the total solar irradiance which is also referred to as Solar Constant. Recent studies have shown that the accuracy of the latter is about $1 \mathrm{~W} / \mathrm{m}^{2}$ (Crommelynck et al., 1995), (Dewitte et al., 2001), thus being also the accuracy of the incoming solar flux product. Validation of the thermal emitted flux and the reflected solar flux was carried out over different surface types. It is based on a comparison of results against Meteosat-7 retrieval results and an intercomparison of GERB and CERES radiance data. 

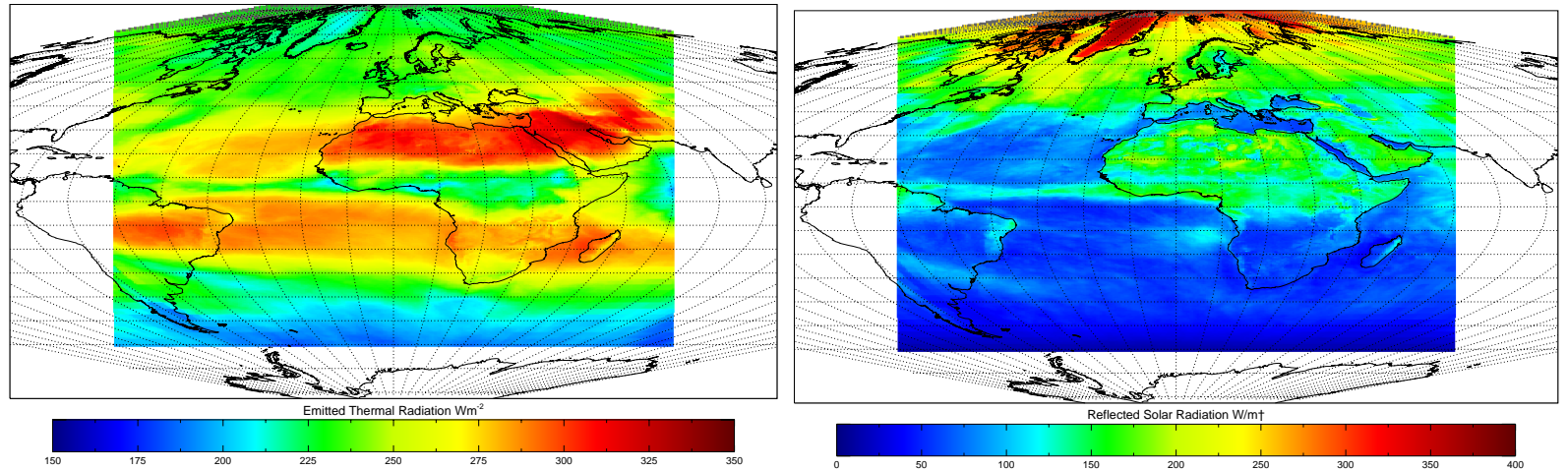

Fig. 7. Top of atmosphere monthly mean data for June 2007 of thermal emitted (left panel) and reflected solar flux (right panel), respectively.

We compared GERB on Meteosat 8 with all active CERES instruments. There were four active CERES instruments up to March 2005, three active CERES instruments from March 2005 onwards. For the thermal emitted flux, also referred to as Outgoing Longwave Radiation (OLR), GERB is $1-2 \%$ lower than CERES. For the reflected solar flux, GERB is $6 \%$ higher than CERES. The latest analysis of the reflected solar radiance GERB CERES differences indicates that they are independent of scene type, therefore they can be considered as a basic calibration difference. For the CM-SAF radiative fluxes (both emitted thermal and reflected solar), the GERB calibration level is used. For the CM-SAF, the GERB and CERES radiances are within acceptable agreement, i.e., within postulated error margins.

\subsection{Surface radiation fluxes}

Incoming and outgoing solar and thermal radiative fluxes are also computed at the surface. The surface radiation algorithms apply the pre-calculated cloud mask, cloud top pressure and cloud type as input.

\subsubsection{Incoming solar radiation}

The calculation of the surface incoming solar radiation (SIS) is based on the method of (Pinker and Laszlo, 1992) and (Mueller et al., 2004). Based on the basic principle of conservation of energy in an atmospheric column, the broadband atmospheric transmittance can be retrieved by measuring reflectance at the top of the atmosphere. For the reflectance at the top of the atmosphere GERB data are used. The reflectance at the top of atmosphere is affected by the atmospheric (e.g., clouds and aerosol) and surface (e.g., albedo) state. The inherent symmetry and an analysis of the partial contribution of each independent variable to the inversion problem have been used to reduce the number of entries in a look-up-table (LUT) scheme. The basis look-up tables for the retrieval have been calculated for three cloud optical depths, 10 aerosol optical depths, 3 single scattering albedos,
2 asymmetry parameters, 6 sun zenith angles and 7 surface albedos. The effect of variations in water vapor and ozone relative to the fixed values used in the calculation of the basis LUT is corrected by using parameterization formulas derived from the radiative transfer models. These look-up tables are finally used to derive the solar irradiance from the TOA albedo for a given surface albedo and atmospheric state by interpolation.

\subsubsection{Downwelling longwave radiation}

For the surface downwelling longwave radiation we adapted the algorithm developed by (Gupta, 1989) and (Gupta et al., 1992). The parametrization requires the temperature profile of the lowest layers of the atmosphere, the water vapor profile and the cloud base height. All atmospheric data used in the surface flux retrieval as well as for the surface albedo calculations are taken from Numerical Weather Prediction (NWP) models. Here, the CM-SAF operational processing employs analysis data of the General Circulation Model (GME) of the German Meteorological Service (DWD) with a spatial resolution of about $40 \mathrm{~km}$, a temporal resolution of three hours and 40 atmospheric layers up to $10 \mathrm{hPa}$ (Majewski et al., 2002). The outgoing longwave flux at surface level is obtained from the Stefan-Boltzmann equation and a surface emissivity that depends on the surface type. The USGS land-typ classification is used as background data for surface types. Wilber et al. (1999) compiled for this a set of 20 different land classes and corresponding emissivity data.

\subsubsection{Surface albedo}

The broadband surface albedo at cloud free pixels is derived as follows: Firstly, the angular-dependent surface reflectance from the top of atmosphere reflectance (per channel) is computed by removing the atmospheric signal caused by gaseous absorption, molecular and aerosol scattering. For this the forward model SMAC (Rahman and Dedieu, 1994) has been used for the required radiative transfer simulations. 
NCEP grid

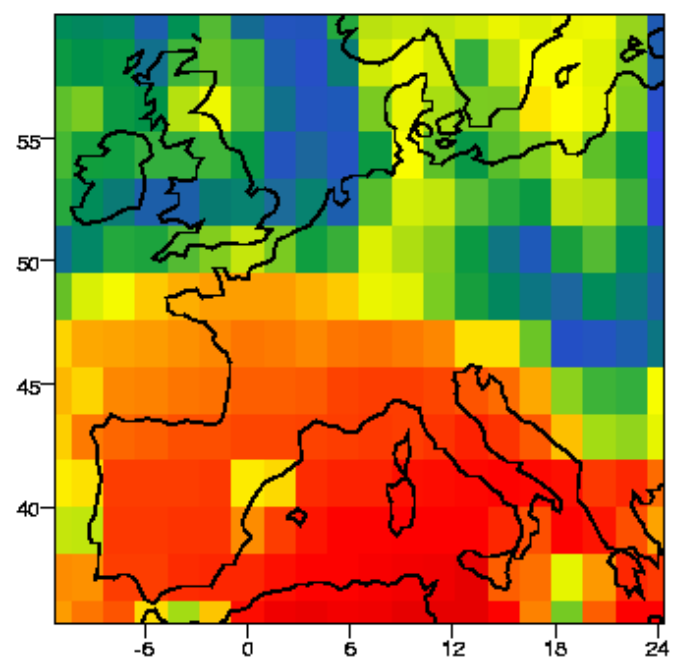

CM-SAF grid

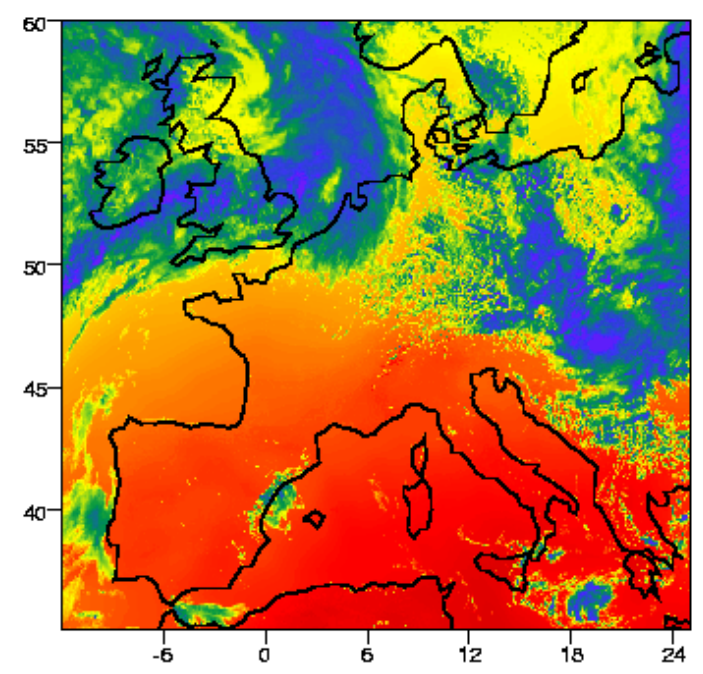

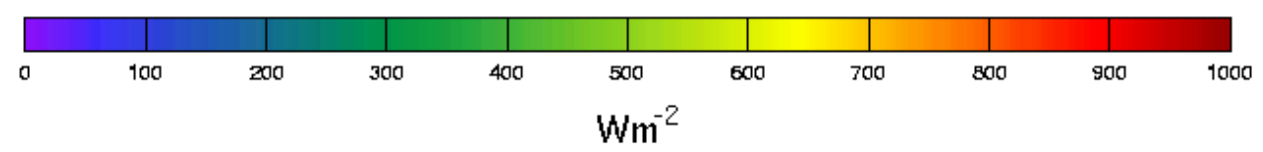

Fig. 8. Incoming solar radiation at surface level at NCEP (left panel) and CM-SAF (right panel) spatial resolution, respectively. Data from Meteosat-8/SEVIRI of 31st August 2006, 10:45 UTC.

Viewing and illumination conditions are corrected employing bidirectional reflectance distribution functions for different surface types. There are six different surface types used in the algorithm, namely barren, forest, cropland, grassland, snow/ice, and ocean. The source for the data is a combined USGS/Corine 2000 land use classification dataset. The surface albedo is then calculated from surface reflectance data as suggested by Roujean et al. (1992). The broadband surface albedo is estimated from a narrow- to broadband conversion (Liang, 2000). The instantaneous surface albedo is finally computed by normalization to a solar zenith angle of $60^{\circ}$.

\subsubsection{Averaging procedure}

Climatological studies require daily averages of the radiation fluxes. For the polar orbiter products the daily averages of the longwave flux are derived by linearly averaging all available, but at least three NOAA overpasses during the day. The daily mean value of SIS is derived following the method presented in Diekmann et al. (1988) which takes into account the diurnal variation of the solar incoming clear-sky flux. Again, three overpasses per day must be at least available. Monthly averages require again at least twenty daily mean products. A daily mean is not feasible for surface albedo as usually the clear sky area is rather small compared to the cloudy area. Instead a weekly and monthly mean albedo is calculated from the instantaneous estimates.

\subsubsection{Product examples}

As an example and to demonstrate the need for highresolution climatological data we show the incoming solar radiation based on SEVIRI data at surface level both on the spatial grids of the CM-SAF product and the National Centers for Environmental Prediction (NCEP) reanalysis (Fig. 8). Clearly, the much higher spatial resolution of CM-SAF is beneficial for many applications, not only for climate issues but also for e.g., the solar energy community which is interested in radiation maps of European areas. Two other product examples, monthly mean results of September 2007 of the surface albedo and the surface radiation budget based on METEOSAT-9/SEVIRI observations are shown in Figs. 9 and 10 , respectively.

The surface radiation flux products are used to evaluate regional climate models. Surface albedo is being used for ice cover breakup studies in Northern Europe and for monitoring of draughts. Estimates of the surface radiation budget can be used in conjunction with estimates of turbulent heat fluxes to investigate the net energy balance at the surface.

\subsubsection{Validation}

The radiation products are validated against ground-based measurements, whereby mainly Baseline Surface Radiation Network (BSRN) stations are used (Ohmura et al., 1998), 


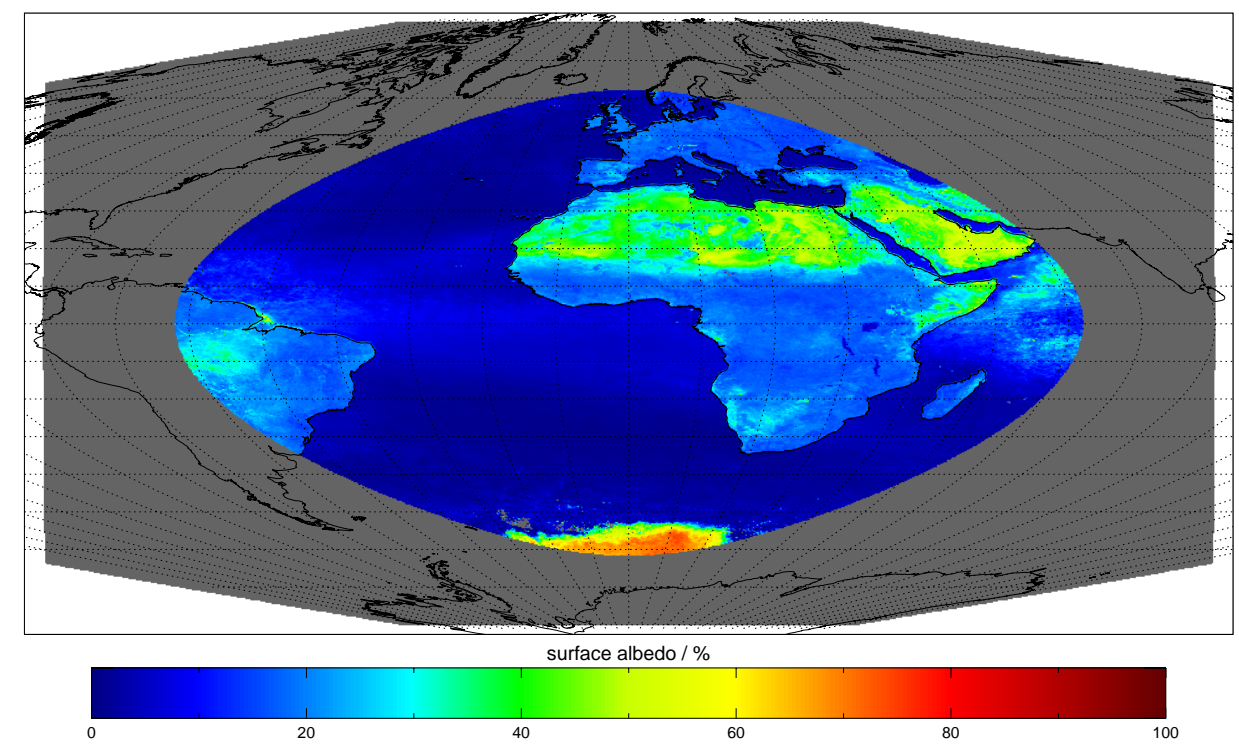

Fig. 9. Monthly mean surface albedo for September 2007 derived from Meteosat-9/SEVIRI observations.

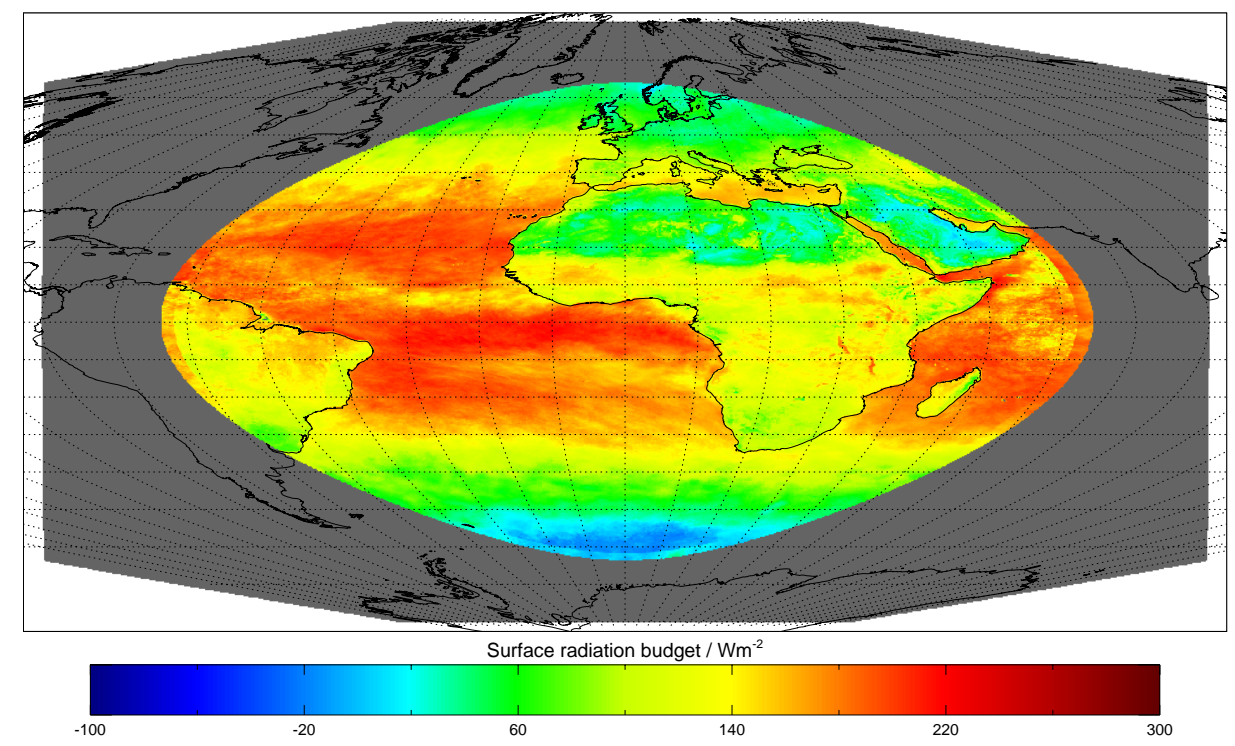

Fig. 10. Monthly mean surface radiation budget for September 2007 derived from Meteosat-9/SEVIRI observations.

supplemented by specific well maintained measurements from European national weather services. Validation of the instantaneous satellite derived data vs. hourly averaged surface measurements of the longwave components and the solar incoming irradiance (SIS) showed good agreement within the targeted accuracy of $10 \mathrm{~W} / \mathrm{m}^{2}$ for monthly averages. Larger deviations of the thermal radiation and the solar incoming radiation are however found over complex terrain where ground-based measurements are not necessarily representative for larger areas of the size of satellite pixels (Hollmann et al., 2006).
It is essential to carefully consider the location of the station (height above sea level, horizontal view restrictions, multiple reflection effects, shadow effects) relative to the surrounding area. Furthermore, local meteorological conditions of e.g., measurement sites in valleys may considerably hamper the interpretation of validation results. On the other hand, the spatial resolution of SEVIRI-based products cannot properly resolve the small-scale spatial variability of mountainous terrain. It seems further that the separation of clouds and snow-covered scenes suffers from the low spatial resolution of the standard solar SEVIRI channels. Thus, it 

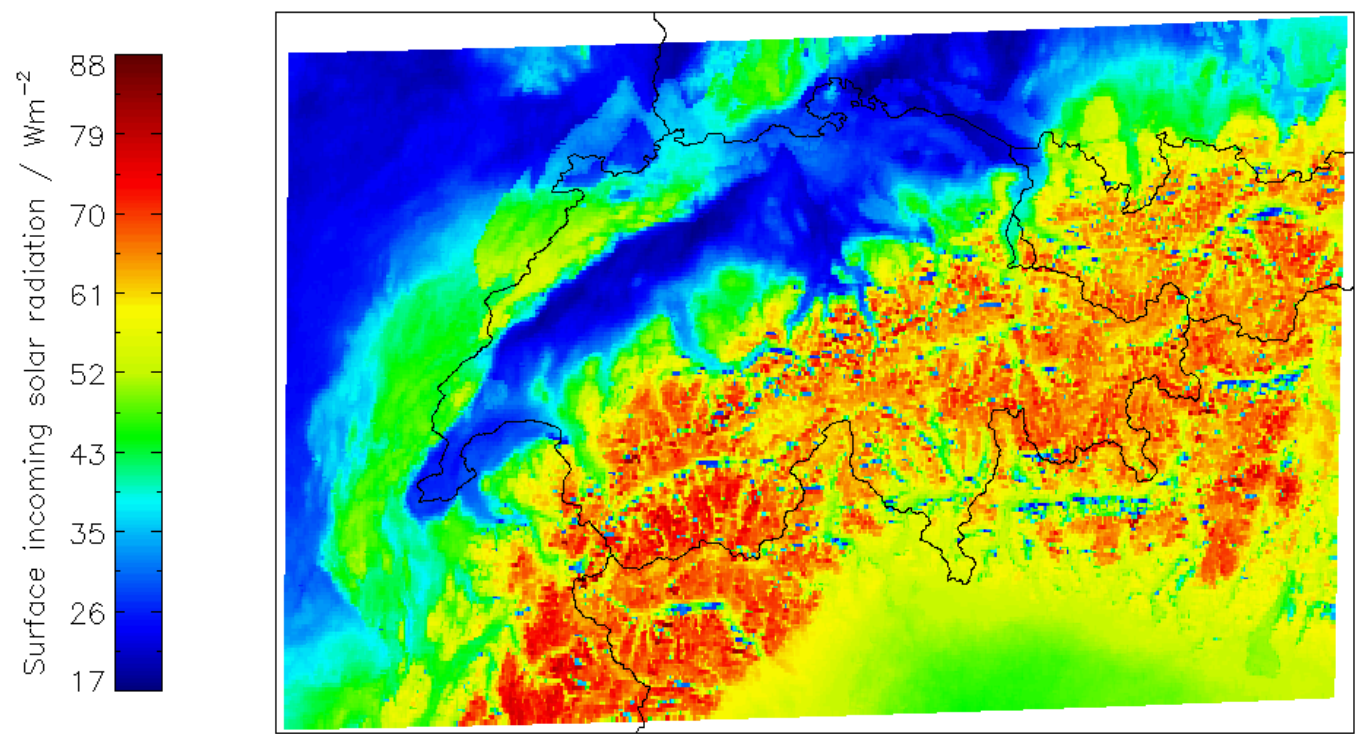

Fig. 11. Monthly mean incoming solar radiation of December 2006 at surface level over complex terrain in Switzerland derived from Meteosat-8/SEVIRI observations. Here, slope and aspect from a high-resolution digital elevation model were used in the retrieval and the incoming solar radiation is clearly lower in valleys.

Weissfluhjoch, $2690 \mathrm{~m}$ asl
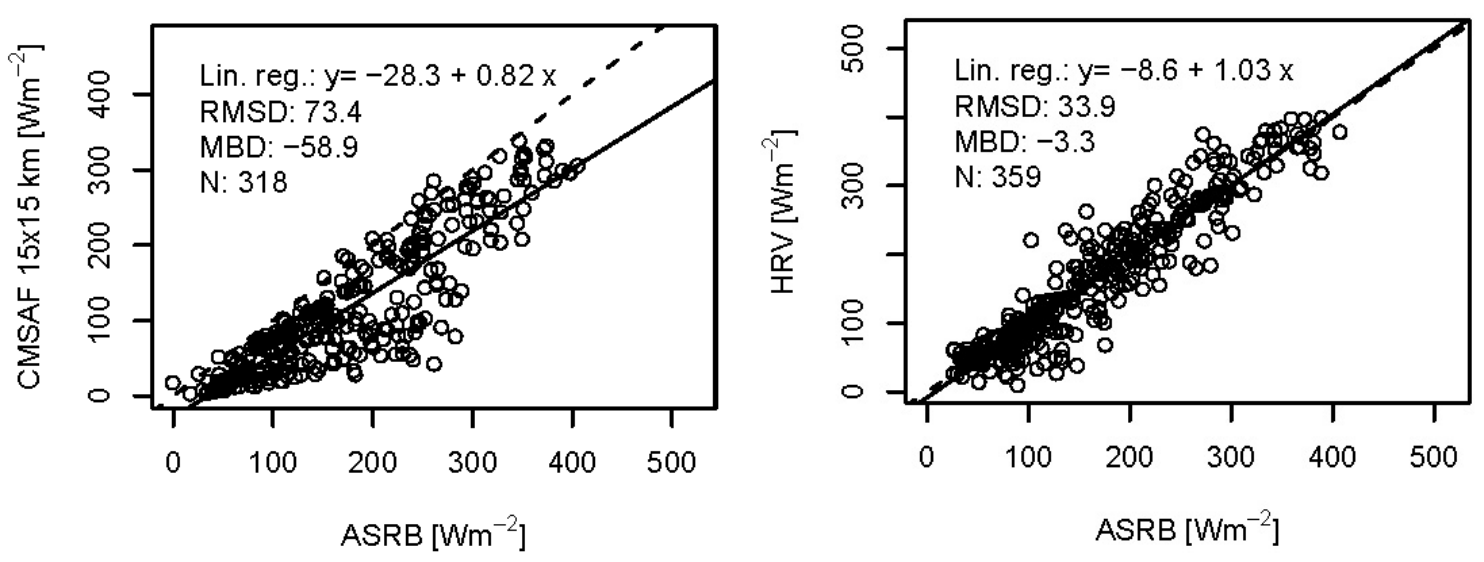

Fig. 12. Comparison of daily solar incoming radiation derived from SEVIRI solar channels (left panel) and the SEVIRI HRV channel (right panel) against ground-based measurements taken at Weissfluhjoch (Switzerland) for the period August 2004 - July 2005.

is considered to introduce an improved SIS product that is based on the high-resolution visible (HRV) channel of SEVIRI and a digital elevation model to take into account topographic effects (Dürr and Zelenka, 2008). As can be seen in Fig. 11 the calculated incoming solar radiation based on HRV data differs remarkably from the standard product. Validation of the solar incoming radiation against ground-based measurements taken from the Alpine Surface Radiation Budget network (ASRB) clearly shows the beneficial impact of the high-resolution channel (Fig. 12). The scatter of SIS re- sults is reduced and the negative bias of the SIS standard product disappears if HRV data is used.

The relative accuracy of the surface albedo is approximately $25 \%$ with respect to ground-based measurements. This is the expected accuracy from the used space born sensors. However, surface albedo retrieved from the geostationary SEVIRI instrument and the AVHRRR instrument systematically differ in their mean value. The reason for this bias is not fully understood and currently under investigation. 


\section{Summary and future perspectives}

CM-SAF as part of EUMETSAT's SAF network provides satellite-derived thematic climate data records. The CM-SAF products comprise macrophysical and cloud physical variables as among others cloud cover and cloud optical thickness, vertically resolved temperature and water vapor information as well as resulting radiation fluxes at the top of the atmosphere and the surface. Spatial coverage of the products ranges from regional (AVHRR derived cloud parameters) over continental (SEVIRI full disc products) to global (ATOVS and SSM/I water vapor products). Temporal coverage is rather short for most of the CM-SAF data products because the operational production started in 2005 and no processing of historical data was foreseen. The exception of this is the SSM/I water vapor series that covers a period from 1987-2005.

CM-SAF utilizes most up to date retrieval schemes to derive its products from operational satellite sensors. Validation results as described above revealed encouraging results for all products, although particular problems as the systematic difference between surface albedo derived from AVHRR and SEVIRI remain to be solved. Currently, available products can already be used for several applications including variability analysis at diurnal to subseasonal time scales, improvements of cloud parameterizations in climate models, etc. Series based on already intercalibrated data as the CERES referenced top of the atmosphere radiation fluxes and the intersensor calibrated SSM/I water vapor data can also be used for studies of interannual variability. Solar radiation fluxes at the surface are also beneficial for the solar energy community.

Based on recommendations from GCOS, the WMO Space Programm, and EUMETSAT, CM-SAF has identified four key issues for the future development of the CM-SAF data sets in a time frame of 5-10 years. These are:

\section{Calibration}

Requirements for more accurate satellite information products are steadily increasing. To create the stable long-term data sets needed for monitoring climate change it becomes vital to inter-calibrate sensors on similar and different satellites. To integrate observations and products from different satellite systems, the measurements must be inter-calibrated. For instance Roebeling et al. (2006) investigated the differences between cloud properties derived from SEVIRI on Meteosat-8 and AVHRR on the NOAA-17 platform. It showed clearly the need of intercalibration before integration. Otherwise the data cannot be used for climate applications because jumps (systematic biases) can occur in a time series constructed from different sensor observations.

Relative calibration of satellite data is a pre-requisite for a reasonable processing of data obtained from dif- ferent sensors of the same type. Current schedule of MSG launches shows that data from three spacecrafts will need to be harmonised until 2012. It is however expected that the satellite operator (EUMETSAT) will provide such radiance data sets towards the end of the CDOP.

First attempts to generate sensor intercalibrated brightness temperature time series from SSM/I records have already been undertaken in the framework of the HOAPS-3 data set (Andersson et al., 2009). Those basic data have already been used to build the SSM/I water vapor product. Furthermore, it is envisaged to retrieve global cloud products using the satellite intercalibration that was developed to generate the PATMOS-X data set (Jacobowitz et al., 2003), but replacing the retrieval methods with CM-SAF cloud algorithms. Such complementary time series would be quite helpful to identify algorithm weaknesses and strengths.

International activities like the Global Space-based Inter-Calibration System (GSICS) initiative strongly help to fulfil some of the CM-SAF needs with respect to data sets and methods during the CDOP. However, some intercalibration activities may have to be pursued by CM-SAF especially in those cases where non EUMETSAT sensors like the SSM/I are used or newer instruments like SEVIRI shall be homogenised with older instruments like MVIRI on the Meteosat first generation in due time. The global network of Regional Specialized Satellite Centers on Climate Monitoring (R/SSC$\mathrm{CM})$ planned by WMO will help to foster the international collaboration in the generation of intercalibrated radiance records. The R/SSC-CM will also help to organize the production and quality assessment of geophysical data sets derived from the intercalibrated radiance records.

2. Temporal extension of the data sets and reprocessing of current products based on homogenised sensor data and employing improved retrieval schemes that are not changed during the processing

As mentioned in the Introduction climate change and variation occur on different time scales and data sets useful for climate monitoring must therefore cover longer time series to understand these changes. The demands on the accuracy increase accordingly to the time scales considered.

Today the existing CM-SAF data from class CDR-I are suitable for monitoring diurnal and subseasonal to seasonal fluctuations of environmental variables which can be large. Currently, CM-SAF started to process historical satellite data to ensure that its data sets may become suitable for analysis of interannual variability and trend detection, i.e. the data sets are developed to fulfil requirements for the classes CDR-II and III. 
Furthermore, improvements of retrieval algorithms and the growing time series of newer instruments such as SEVIRI that are affected by calibration changes will cause reprocessing of these data sets within the period 2007 to 2012. Both activities imply close interaction of responsible space agencies in order to archive and provide the required data in the given time frame. Such reprocessing events also need to be carefully coordinated with data suppliers (upstream) and the user community (downstream).

\section{The production of global and regional products}

Climate variability at regional level may be related to global climate changes but regional effects may differ from region to region. CM-SAF aims to provide support for climate analysis at regional level but needs global products to improve the understanding of scale interaction and to interpret the nature of regional changes. Global products enhance the amount of possible applications, e.g., global products can be used to support studies on climate sensitivity of global climate models. However, the extension to global products is not possible for all products because of the inhomogeneity of the observing system. This is especially true for instruments in geostationary orbit where the SEVIRI instrument sets new standards but dedicated algorithms cannot be applied globally. Additionally, collaboration between at least four satellite operators would be needed to achieve an almost global product. Regional products derived from SEVIRI with improved quality will still serve as regional benchmark data sets. Products from polar orbiters typically suffer from inadequate spatiotemporal sampling at low latitudes but provide complementary data with often better spatial resolution. However, at high latitudes polar orbiter data are essential to study polar conditions.

4. The integration of new products that facilitate a better understanding of the energy and water cycle

The primary strength of the CM-SAF approach for climate monitoring is the provision of consistent thematic climate data records. One of the most concerning questions about the changing Earth climate system is the potential change of the hydrological and energy cycle. Energy and water cycle related geophysical parameters over water surfaces at global scale are provided by the Hamburg Ocean Atmosphere Parameters and Fluxes from Satellite Data (HOAPS-3) (Andersson et al., 2009). Consequently, CM-SAF will take over the responsibility for the processing of HOAPS during the CDOP. This will enhance the product suite with precipitation and turbulent heat fluxes over the ocean. Potentially, the CM-SAF surface flux products can be used to investigate the net heat flux at the ocean surface.
A 30 year long climatology of upper tropospheric humidity derived from a homogenized Meteosat record spanning over Meteosat First and Second Generation instruments will be derived in cooperation with the Laboratoire Météorologie Dynamique (LMD). It will provide a very good data set to study the variability of water vapor at intraseasonal scale. Brogniez et al. (2006) found from a series of Meteosat First Generation data for the period 1983-2005 an asymmetry between the two hemispheres along the annual cycle. Whereas the intra-seasonal variability is homogeneous in the Southern Hemisphere the variability shows a distinct minimum in the Northern Hemisphere during the summer. Thus, the planned data set extended with data from the new SEVIRI instrument will be perfectly usable to analyse the quality of intra-seasonal variability in future global reanalysis. Other new products include ice water path, aerosol properties and enhanced surface radiation flux products as a spectrally resolved irradiance.

Acknowledgements. We acknowledge the Cloudnet project (European Union contract EVK2-2000-00611) for providing the microwave radiometer and target classification data, which was produced by the University of Reading using measurements from the expirimental sites of Chilbolton in the UK, Paleaseau in France and Cabauw in the Netherlands. The supportive work of the EUMETSAT secretary is greatly acknowledged. We thank the NWCSAF consortium for providing the NOAA/PPS and MSG/SEVIRI retrieval packages.

The authors are indebted to the work of the CM-SAF team in particular L. Schreiber, D. Stein, S. Villbrandt, R. Weber for supporting the technical development of the CM-SAF processing scheme, R. Cremer for supporting the validation activities, B. Thiess and P. Willing for handling the CM-SAF User Help Desk and finally W. Mehley for administrative support of the whole activity.

We are grateful to R. Lindau (Univ. Bonn, Germany) and A. Walther (Freie Univ. Berlin, Germany) for their valuable work with the Kriging algorithm and the validation of water vapor products, respectively. We thank the colleagues at Deutscher Wetterdienst at Offenbach and the meteorological observatory Lindenberg for providing NWP analysis data and ground-based measurements that were used to validate several CM-SAF products.

Edited by: J. Brandt

\section{References}

Allan, R., Slingo, A., Milton, S., and Brooks, M.: Evaluation of the Met Office global forecast model using Geostationary Earth Radiation Budget (GERB) data, Q. J. Roy. Meteor. Soc., 133, 1993-2010, 2007.

Andersson, A., Klepp, C., Fennig, K., Bakan, S., Grassl, H., and Schulz, J.: The HOAPS climatology: Essential water cycle components over global oceans derived from satellite data, B. Am. Meteorol. Soc., submitted, 2009. 
Boers, R., van Lammeren, A., and Feijt, A.: Accuracy of cloud optical depth retrievals from ground based pyranometers, J. Atmos. Ocean. Tech., 17, 916-927, 2000.

Brogniez, H., Roca, R., and Picon, L.: A clear-sky radiance archive from Meteosat water vapor observations, J. Geophys. Res., 111, D21109, doi:10.1029/2006JD00723, 2006.

Clerbaux, N., Dewitte, S., Gonzalez, L., Bertrand, C., Nicula, B., and Ipe, A.: Outgoing longwave flux estimation: improvement of angular modelling using spectral information, Remote. Sens. Environ., 85, 389-395, 2003.

Colton, M., Karl, T., Goldberg, M., and Bates, J.: Creating Climate Data Records from NOAA Operational Satellites, White paper, National Oceanic And Atmospheric Administration, National Environmental Satellite, Data, and Information Service, 53 pp., 2003.

Crommelynck, D., Fichot, A., III, R. L., and Romero, J.: First realisation of the Space Absolute Radiometric Reference during the ATLAS 2 flight period, Adv. Space Res., 16, 17-23, 1995.

Deneke, H., Feijt, A., van Lammeren, A., and Simmer, C.: Validation of a physical retrieval scheme of solar surface irradiances from narrowband satellite radiances, J. Appl. Meteorol., 44, 1453-1466, 2005.

Derrien, M. and LeGléau, H.: MSG/SEVIRI cloud mask and type from SAFNWC, Int. J. Remote. Sens., 26, 4707-4732, 2005.

Derrien, M., Farki, B., Harang, L., Gléau, H. L., Noyalet, A., Pochic, D., and Sairouni, A.: Automatic cloud detection applied to NOAA-11 / AVHRR imagery, Remote. Sens. Environ., 46, 246-267, 1993

Dewitte, S., Joukoff, A., Crommelynck, D., III, R. L., Helizon, R., and Wilson, R.: Contribution of the SOLCON program to the long term total solar irradiance observation, J. Geophys. Res., 106, 759-766, 2001.

Dewitte, S., Crommelynck, D., and Joukoff, A.: Total solar irradiance observations from DIARAD/VIRGO, J. Geophys. Res., 109, A02102, doi:10.1029/2002JA009694, 2004.

Diekmann, F.-J., Happ, S., Rieland, M., Benesch, W., Czeplak, G., and Kasten, F.: An operational estimate of global solar irradiance at ground level from METEOSAT data: results from 1985 to 1987, Meteorol. Rundsch., 41, 65-79, 1988.

Dürr, B. and Zelenka, A.: Satellite derived surface global irradiance over the Alpine region from METEOSAT Second Generation data, Int. J. Remote Sens., accepted, 2009.

Dybbroe, A., A. Thoss, A., and Karlsson, K.-G.: SAFNWC AVHRR cloud detection and analysis using dynamic thresholds and radiative transfer modelling Part I: Algorithm description, J. Appl. Meteorol., 44, 39-54, 2005a.

Dybbroe, A., Thoss, A., and Karlsson, K.-G.: SAFNWC AVHRR cloud detection and analysis using dynamic thresholds and radiative transfer modelling Part II: Validation, J. Appl. Meteorol., 44, 55-71, 2005b.

GCOS: The second report on the adequacy of the global observing systems for climate in support of UNFCCC, Technical Document GCOS - 82, WMO/TD No. 1143, World Meteorological Organization, Geneva, Switzerland, 2003.

GCOS: Implementation Plan for the Global Observing System For Climate in support of the UNFCCC, Technical Document GCOS - 92, WMO/TD No. 1219, World Meteorological Organization, Geneva, Switzerland, 2004.

GCOS: GCOS Reference Upper-Air Network (GRUAN): Justifica- tion, requirements, siting and instrumentation options, Technical Document GCOS - 112, WMO/TD No. 1379, World Meteorological Organization, Geneva, Switzerland, 2007.

Gupta, S.: A parameterization for longwave surface radiation from sun-synchronous satellite data, J. Climate, 2, 305-320, 1989.

Gupta, S., Darnell, L., and Wilber, A.: A parameterization for longwave surface radiation from satellite data: recent improvements, J. Appl. Meteorol., 31, 1361-1367, 1992.

Gupta, S. K., Ritchey, N. A., Wilber, A. C., Whitlock, C. H., Gibson, G. G., and Stackhouse Jr., P. W.: A climatology of surface radiation budget derived from satellite data, J. Climate, 12, 26912710, 1999.

Haan, J. D., Bosma, P., and Hovenier, J.: The adding method for multiple scattering calculations of polarized light, Astron. Astrophys., 183, 371-391, 1987.

Harries, J., Russell, J., Hanafin, J., Brindley, H., Futyan, J., Rufus, J., Kellock, S., Matthews, G., Wrigley, R., Last, A., Mueller, J., Mossavati, R., Ashmall, J., Sawyer, E., Parker, D., Caldwell, M., Allan, P., Smith, A., Bates, M., Coan, B., Stewart, B., Lepine, D., Cornwall, L., Corney, D., Ricketts, M., Drummond, D., Smart, D., Cutler, R., Dewitte, S., Clerbaux, N., Gonzalez, L., Ipe, A., Bertrand, C., Joukoff, A., Crommelynck, D., Nelms, N., Llewellyn-Jones, D., Butcher, G., Smith, G., Szewczyk, Z., Mlynczak, P., Slingo, A., Allan, R., and Ringer, M.: The Geostationary Earth Radiation Budget Project, B. Am. Meteorol. Soc., doi:10.1175/BAMS-86-7-945, 945-960, 2005.

Held, I. and Soden, B.: Water vapor feedback and global warming, Annu. Rev. Energy Env., 25, 441-475, 2000.

Hollmann, R., Müller, R., and Gratzki, A.: CM-SAF surface radiation budget: First results with AVHRR data, Adv. Space Res., 37, 2166-2171, 2006.

Illingworth, A. J., Hogan, R. J., O'Connor, E. J., et al.: Continuous evaluation of cloud profiles in seven operational models using ground-based observations, B. Am. Meteorol. Soc., 88, 6, 883898, 2007.

Inoue, T.: A cloud type classification with NOAA-7 split-window measurements, J. Geophys. Res., 92, 3991-4000, 1987.

Jacobowitz, H., Stowe, L., Ohring, G., Heidinger, A., Knapp, K., and Nalli, N.: The Advanced Very High Resolution Radiometer Pathfinder Atmosphere (PATMOS) climate dataset: A resource for climate research, B. Am. Meteorol. Soc., 84, 785-793, 2003.

Jolivet, D. and Feijt, A. J.: Cloud thermodynamic phase and particle size estimation using the 0.67 and $1.6 \mu \mathrm{m}$ channels from meteorological satellites, Atmos. Chem. Phys. Discuss., 3, 4461-4488, 2003, http://www.atmos-chem-phys-discuss.net/3/4461/2003/.

Karlsson, K.: A 10 year cloud climatology over Scandinavia derived from NOAA advanced very high resolution radiometer imagery, Int. J. Climatol., 23, 1023-1044, doi:10.1002/joc.916, 2003.

Karlsson, K., Willén, U., Jones, C., and Wyser, K.: Evaluation of regional cloud climate simulations over Scandinavia using a 10-year NOAA Advanced Very High Resolution Radiometer cloud climatology, J. Geophys. Res., 113, D01203, doi:10.1029/2007JD008658, 2008.

King, M.: Determination of the scaled optical thickness from reflected solar radiation measurements, J. Atmos. Sci., 44, 1734 1751, 1987.

Li, J., Wolf, W., Menzel, W., Zhang, W., Huang, H.-L., and Achtor, T.: Global soundings of the atmosphere from ATOVS 
measurements: The algorithm and validation., J. Appl. Meteorol., 39, 1248-1268, 2000.

Liang, S.: Narrowband to broadband conversions of land surface albedo: I. Algorithms, Remote. Sens. Environ., 76, 213-238, 2000.

Lindau, R. and Schulz, J.: Gridding/merging techniques for the humidity composite product of the CM-SAF, vol. EUM P41, 519526, 2004.

Loeb, N., Manalo-Smith, N., Kato, S., Gupta, S., Minnis, P., and Wielicki, B.: Angular distribution models for top-of-atmosphere radiative flux estimation from the Clouds and the Earths Radiant Energy System instrument on the Tropical Rainfall Measuring Mission satellite, J. Appl. Meteorol., 42, 1748-1769, 2003.

Majewski, D., Liermann, D., Prohl, P., Ritter, B., Buchhold, M., Hanisch, T., Paul, G., Wergen, W., and Baumgardner, J.: The operational global icosahedral-hexagonal grid point model GME: Description and high resolution tests, Mon. Weather Rev., 130, 319-338, 2002

Meerkötter, R., König, C., Bissolli, P., Gesell, G., and Mannstein, H.: A 14-year European Cloud Climatology from NOAA//AVHRR data in comparison to surface observations, Geophys. Res. Lett., 31, L15103, doi:10.1029/2004GL020098, 2004.

Menzel, W., Smith, W., and Stewart, T.: Improved Cloud Motion Wind Vector and Altitude Assignment using VAS, J. Clim. Appl. Meteorol., 22, 377-384, 1983.

Mieruch, S., Noël, S., Bovensmann, H., and Burrows, J. P.: Analysis of global water vapor trends from satellite measurements in the visible spectral range, Atmos. Chem. Phys., 8, 491-504, 2008, http://www.atmos-chem-phys.net/8/491/2008/.

Miloshevich, Paukkunen, L. M., Vömel, H., and Oltmans, S. J.: Development and validation of a time-lag correction for Vaisala radiosondes humidity measurements, J. Atmos. Oceanic Tech., 21, 1305-1327, 2004.

Mueller, R., Dagestad, K., Ineichen, P., Schroedter-Homscheidt, M., Cros, S., Dumortier, D., Kuhlemann, R., Olseth, J., Piernavieja, G., Resie, C., Wald, L., and Heinemann, D.: Rethinking satellite based solar irradiance modelling. The SOLIS clear-sky module, Remote Sense. Environ., 91, 160-174, 2004.

Nakajima, T. and King, M.: Determination of the optical thickness and effective particle radius of clouds from reflected solar radiation measurements, part 1: Theory, J. Atmos. Sci., 47, 1878$1893,1990$.

Nakajima, T. and Nakajima, T.: Determination of cloud microphysical properties from NOAA AVHRR measurements for FIRE and ASTEX regions, J. Atmos. Sci., 52, 4043-4095, 1995.

Ohmura, A., Dutton, E., Forgan, B., Froehlich, C., Gilgen, H., Hegner, H., Heimo, A., Koenig-Langlo, G., McArthur, B., Mueller, G., Philipona, R., Pinker, R., Whitlock, C., Dehne, K., and Wild, M.: Baseline Surface Radiation Network (BSRN/WCRP): new precision radiometry for climate research, B. Am. Meteorol. Soc., 79, 10, 2115-2136, 1998.

Ohring, G., Wielicki, B., Spencer, R., Emery, B., and Datla, R.: Satellite Instrument Calibration for Measuring Clobal Climate Change, B. Am. Meteorol. Soc., doi:10.1175/BAMS-86-9-1303, 1303-1313, 2005.

Pinker, R. and Laszlo, I.: Modelling surface solar irradiance for satellite applications on a global scale, J. Appl. Meterol., 31, 194-211, 1992.
Rahman, H. and Dedieu, G.: SMAC: A simplified method for the atmospheric correction of satellite measurements in the solar spectrum, Int. J. Remote. Sens., 15, 123-143, 1994.

Rind, D.: Just Add Water Vapor, Science, 281, 1152-1153, 1998.

Robinson, D., Barry, R., Campbell, J., Defries, R., Emery, W., Hurrell, M. H. J., Laing, A., Miller, R., Myneni, R., R. Somerville, P. T., and Vonder Haar, T.: Climate Data Records from Environmental Satellites: Interim Report, Technical report, National Research Council, Committee on Climate Data Records from NOAA Operational Satellites, 136 pp., 2004.

Roebeling, R., Feijt, A., and Stammes, P.: Cloud property retrievals for climate monitoring: implications of differences between Spinning Enhanced Visible and Infrared Radiometer (SEVIRI) on METEOSAT-8 and Advanced Very High Resolution Radiometer (AVHRR) on NOAA-17, J. Geophys. Res., 111, D20210, doi:10.1029/2005JD0069990, 2006.

Roebeling, R., Deneke, H. M., and Feijt, A.: Validation of cloud liquid water path retrievals from SEVIRI using one year of CloudNET observations, J. Appl. Meteorol. Clim., 47, 206-222, 2008.

Rossow, W. and Garder, L.: Cloud Detection Using Satellite Measurements of Infrared and Visible Radiances for ISCCP, J. Climate, 6, 2341-2369, 1993.

Rossow, W. and Schiffer, R.: ISCCP cloud data products, B. Am. Meteorol. Soc., 72, 2-20, 1991.

Roujean, J.-L., Leroy, M., and Deschamps, P.: A Bidirectional Reflectance Model of the Earths Surface for the Correction of Remote Sensing Data, B. Am. Meteorol. Soc., 97, 20455-20468, 1992.

Santer, B., Mears, C., Wentz, F., Taylor, K., Gleckler, P., Wigley, T., Barnett, T., Boyle, J., Brüggemann, W., Gillett, N., Klein, S., Meehl, G., Nozawa, T., Pierce, D., Scott, P., Washington, W., and Wehner, M.: Identification of human-induced changes in atmospheric moisture content, P. Natl. Acad. Sci. USA, 104, 15248-15253, 2007.

Schlüssel, P. and Emery, W. J.: Atmospheric water vapor over oceans from SSM/I measurements, Int. J. Remote Sens., 11, 753766, 1990.

Schmetz, J., Holmlund, K., Hoffman, J., Strauss, B., Mason, B., Gaertner, V., Koch, A., and van de Berg, L.: Operational CloudMotion Winds from Meteosat Infrared Images, J. Appl. Meterol., 32, 1206-1225, 1993

Schmetz, J., Pili, P., Tjemkes, S., Just, D., Kerkmann, J., Rota, S., and Ratier, A.: An introduction to Meteosat Second Generation (MSG), B. Am. Meteorol. Soc., 83, 977-992, 2002.

Schulz, J., Schlüssel, P., and Grassl, H.: Water vapor in the atmospheric boundary layer over oceans from SSM/I measurements, Int. J. Remote Sens., 14, 2773-2789, 1993.

Soden, B. J.: Atmospheric physics: Enlightening water vapor, Nature, 406, 247-248, 2000.

Sohn, B. and Smith, E.: Explaining sources of discrepancy in SSM/I water vapor algorithms, J. Climate, 16, 3229-3255, 2003.

Stephens, G.: Cloud feedbacks in the climate system: A critical review, J. Climate, 18, 237-273, 2005.

Stephens, G., Paltridge, G., and Platt, C.: Radiation profiles in extended water clouds. III. Observations, J. Atmos. Sci., 35, 2133 2141, 1978.

Trenberth, K., Fasullo, J., and Smith, L.: Trends and variability in column-integrated atmospheric water vapor, Clim. Dynam., 24, 741-758, doi:10.1007/s00 382-005-0017-4, 2005. 
Vonder Haar, T.: Continuation of the NVAP Global Water Vapor Data Sets for Pathfinder Science Analysis, Technical Report 3333, Science and Technology Cooperation, 2003.

Wentz, F.: The intercomparison of $53 \mathrm{SSM} / \mathrm{I}$ water vapor algorithms, Remote Sensing Systems Tech. Rep. on WetNet Water Vapor Intercomparison Project (VIP), Remote Sensing Systems, Santa Rosa, CA, 19 pp., 1995.

Wilber, A., Kratz, D., and Gupta, S.: Surface Emissivity Maps for Use in Satellite Retrievals of Longwave Radiation, Technical Publication TP-1999-209362, NASA Langley Research Center, 1999.
Woick, H., Dewitte, S., Feijt, A., Gratzki, A., Hechler, P., Hollmann, R., Karlsson, K.-G., Laine, V., Löwe, P., Nitsche, H., Werscheck, M., and Wollenweber, G.: The Satellite Application Facility on Climate Monitoring, Adv. Space Res., 30, 2405-2410, 2002.

Wolters, E. L. A., Roebeling, R. A., and Feijt, A. J.: Evaluation of cloud phase retrieval methods for SEVIRI onboard Meteosat- 8 using ground-based lidar and cloud radar data, J. Appl. Meteorol. Clim., 47, 1723-1738, 2008. 